\title{
Semisynthetic Quercetin Derivatives with Potent Antitumor Activity in Colon
}

\section{Carcinoma}

Ayan Mukherjee ${ }^{\dagger} \perp$, Snehasis Mishra ${ }^{\ddagger \perp}$, Naveen Kumar Kotla ${ }^{\dagger}$, Krishnendu Manna ${ }^{\ddagger}$, Swarnali Roy ${ }^{\dagger}$, Biswajit Kundu ${ }^{\dagger}$, Debomita Bhattacharya ${ }^{\dagger}$, Krishna Das Saha ${ }^{\ddagger}$ and Arindam Talukdar t* $^{*}$

$\dagger$ Department of Organic and Medicinal Chemistry, CSIR-Indian Institute of Chemical Biology, 4 Raja S. C. Mullick Road, Kolkata 700032, WB (India).

$\ddagger$ Department of Cancer Biology and Inflammatory Disorders, CSIR-Indian Institute of

Chemical Biology, 4 Raja S. C. Mullick Road, Kolkata, 700032 WB (India)

$\int$ Academy of Scientific and Innovative Research (AcSIR), Ghaziabad- 201002, India

Table of Contents

\begin{tabular}{|l|l|}
\hline Topics & Page no \\
\hline Crystallographic and structural refinement parameters of compound 13 & 2 \\
\hline${ }^{1}$ HNMR, ${ }^{13}$ C NMR spectra for synthesized Compounds & 3 \\
\hline HRMS error data & 25 \\
\hline MTT assay in PBMC and HCT116 Cell line & \\
\hline Schematic representation of the in vivo experimental design & 26 \\
\hline Photo of harvest tumour & 27 \\
\hline
\end{tabular}


Crystallographic and structural refinement parameters of compound 13 (CCDC: 1854629)

\begin{tabular}{|c|c|}
\hline Empirical formula & $\mathrm{C}_{39} \mathrm{H}_{33} \mathrm{Cl} \mathrm{O}_{7}$ \\
\hline Formula weight & 649.10 \\
\hline Temperature/K & 296 \\
\hline Crystal system & monoclinic \\
\hline Space group & $\mathrm{P}-1$ \\
\hline Hall group & $-\mathrm{P} 1$ \\
\hline $\mathrm{a} / \AA$ & 5.0697 \\
\hline $\mathrm{b} / \AA$ & 18.451 \\
\hline $\mathrm{c} / \AA$ & 18.954 \\
\hline$\alpha /^{\circ}$ & 63.346 \\
\hline$\beta /{ }^{\circ}$ & 89.191 \\
\hline$\gamma /{ }^{\circ}$ & 87.073 \\
\hline Volume $/ \AA^{3}$ & 1582.4 \\
\hline $\mathrm{Z}$ & 2 \\
\hline$\rho$ calcg $/ \mathrm{cm}^{3}$ & 1.362 \\
\hline$\mu / \mathrm{mm}-1$ & 0.174 \\
\hline $\mathrm{F}(000)$ & 680.0 \\
\hline Data completness & 0.999 \\
\hline Radiation & $\operatorname{MoK} \alpha(\lambda=0.71073)$ \\
\hline $\mathrm{h}, \mathrm{k}, \mathrm{l} \max$ & $6,21,22$ \\
\hline $\mathrm{R}$ (reflection) & 0.999 \\
\hline CCDC no & 1854629 \\
\hline
\end{tabular}


${ }^{1} \mathrm{H}$ NMR and ${ }^{13} \mathrm{C}$ NMR of Compound 2

Proton NMR
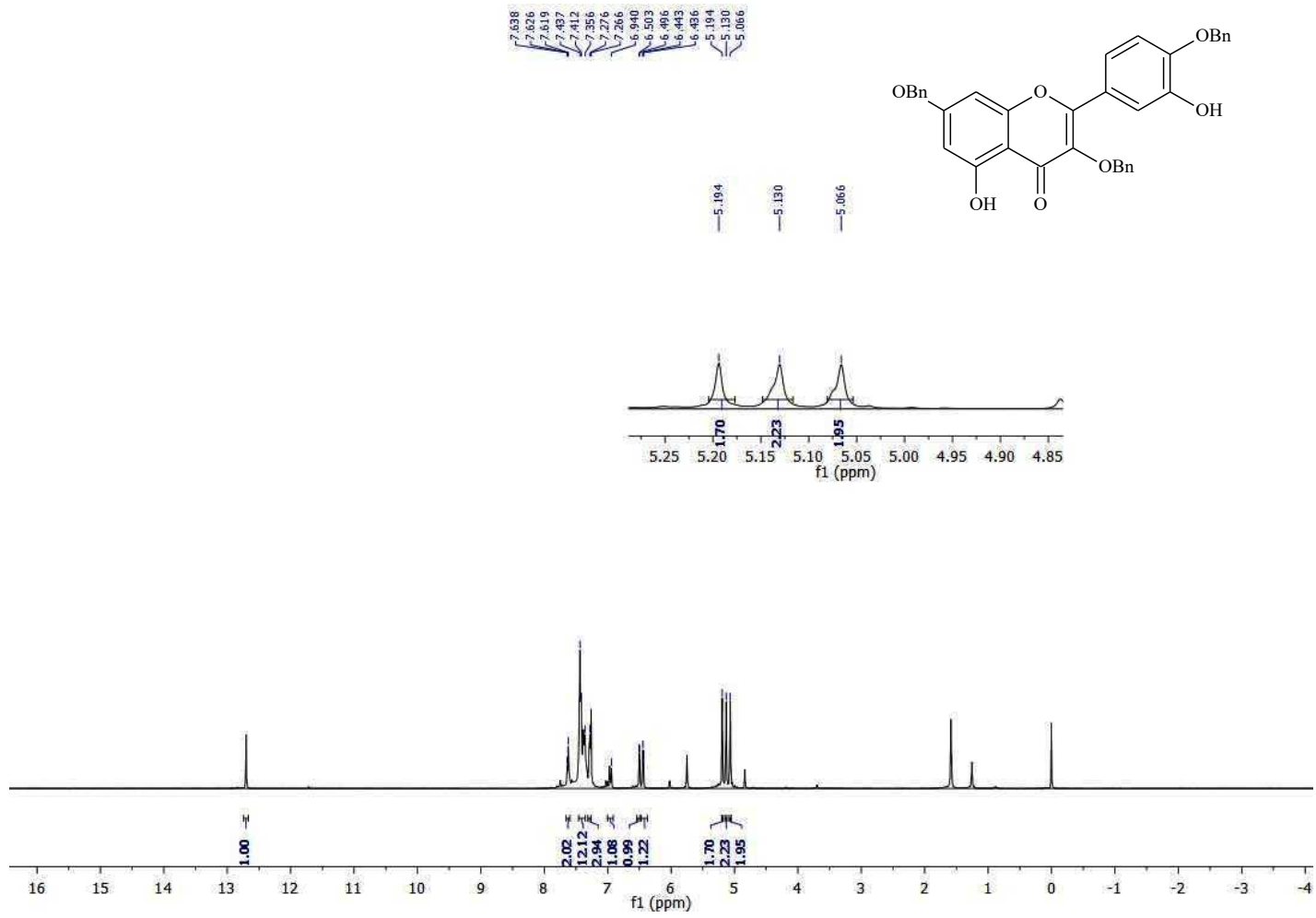

Carbon NMR

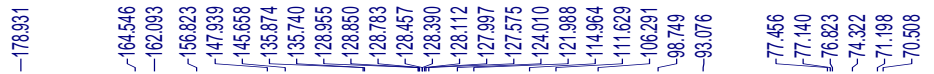

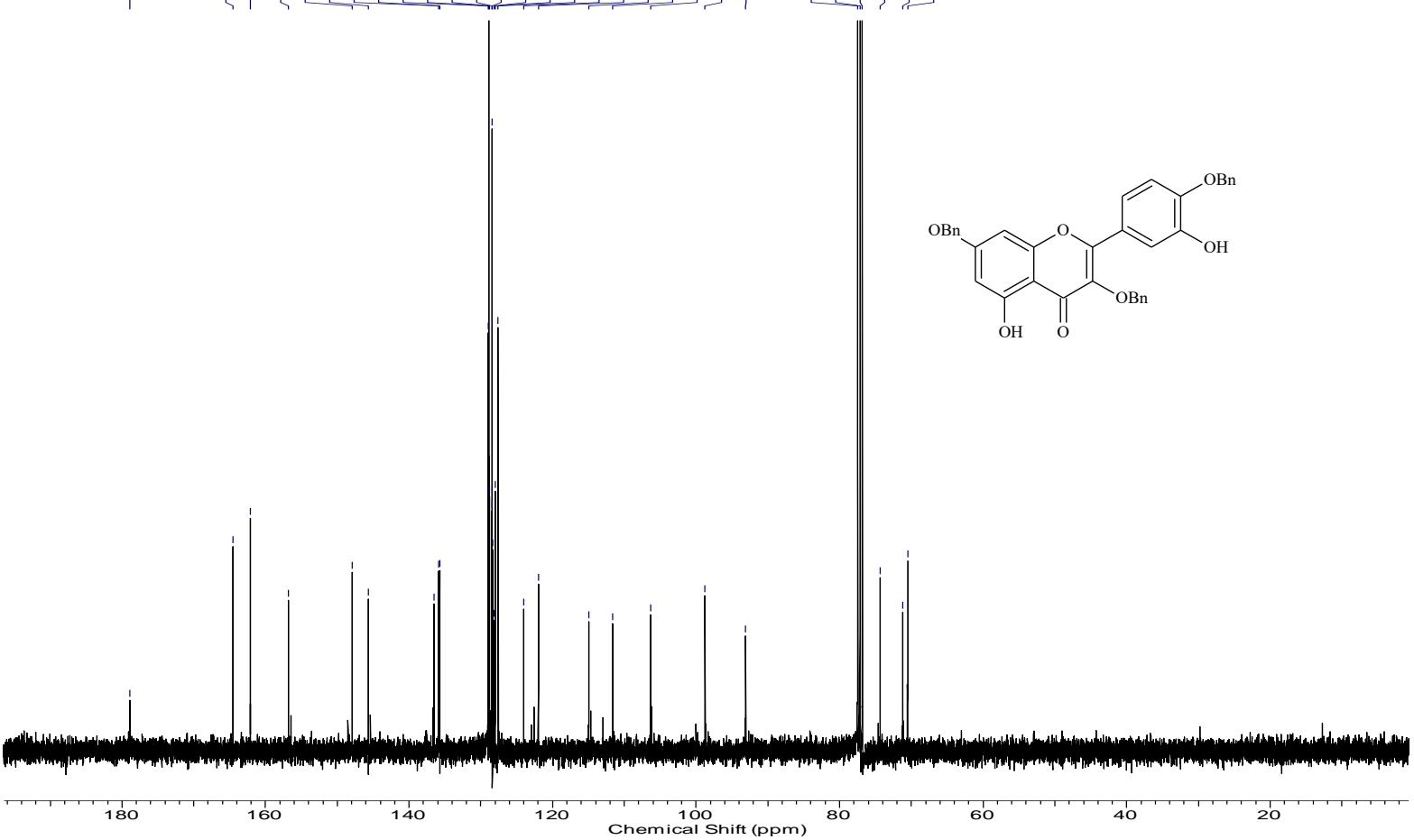


${ }^{1} \mathrm{H}$ NMR and ${ }^{13} \mathrm{C}$ NMR of Compound 3

Proton NMR

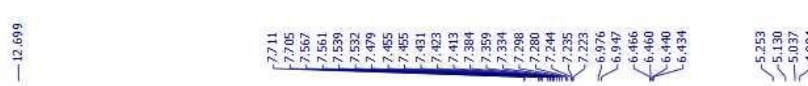
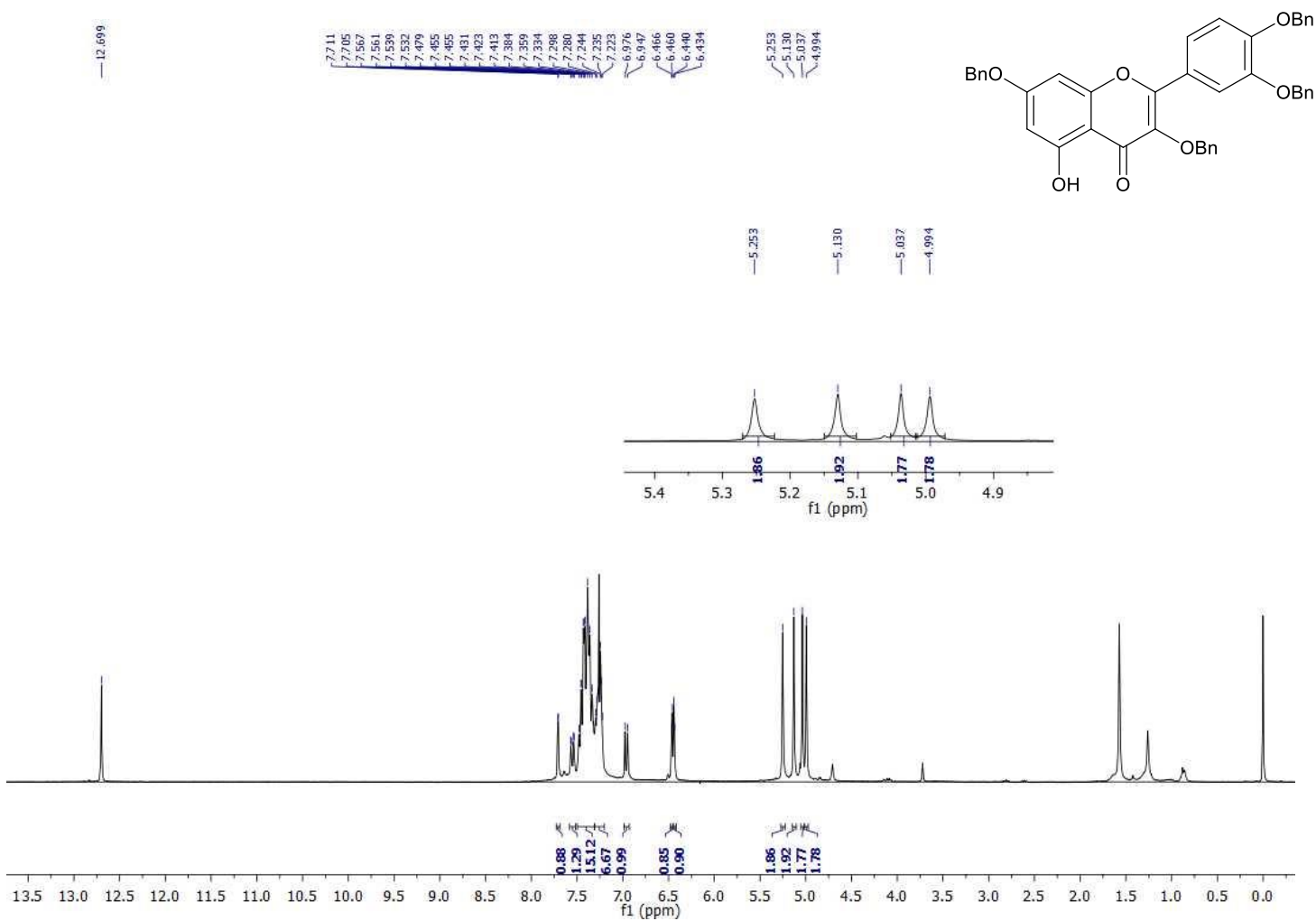

Carbon NMR

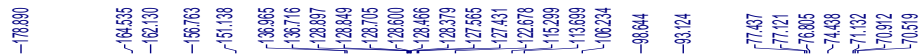

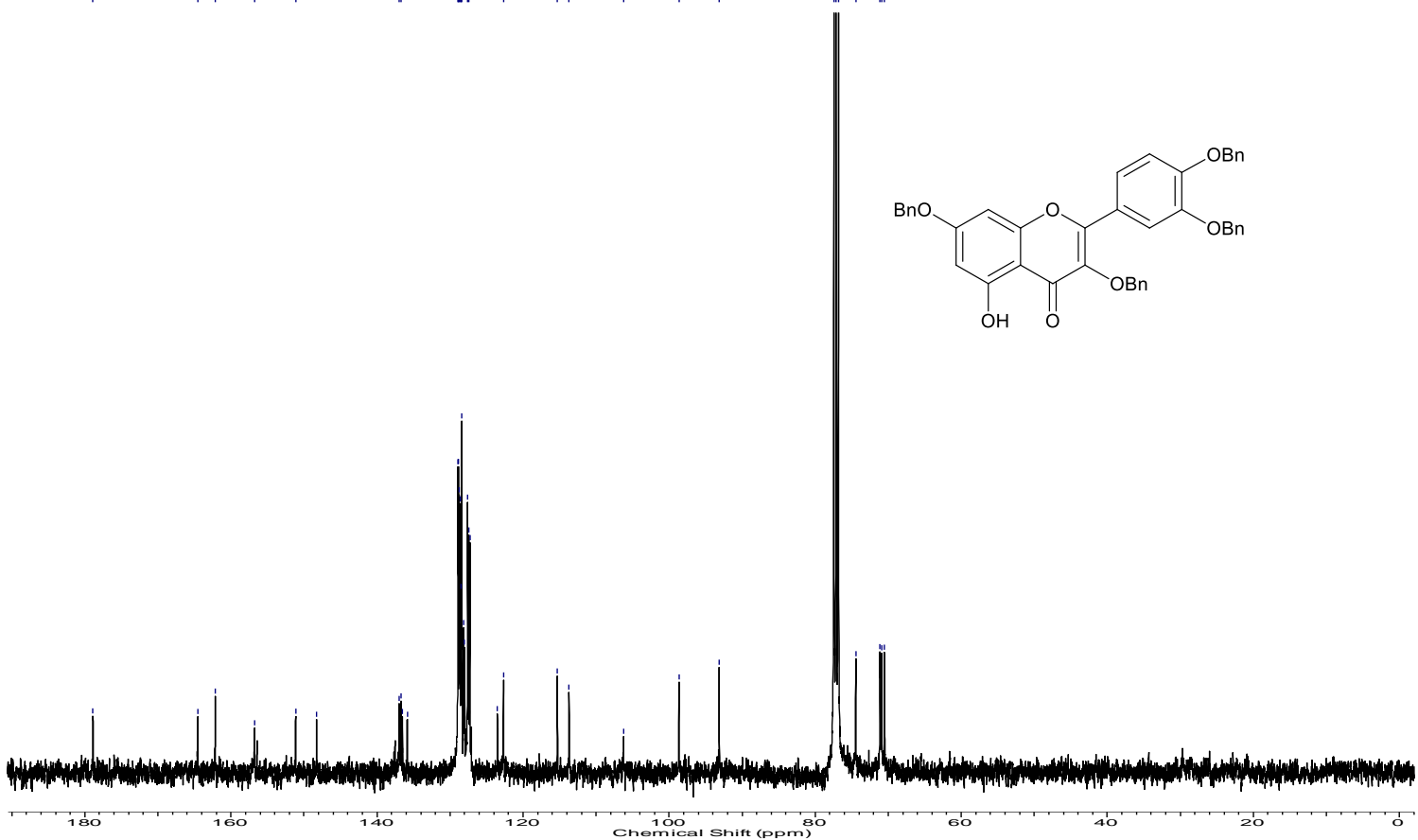


${ }^{1} \mathrm{H}$ NMR and ${ }^{13} \mathrm{C}$ NMR of Compound 4

Proton NMR

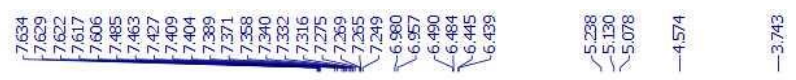

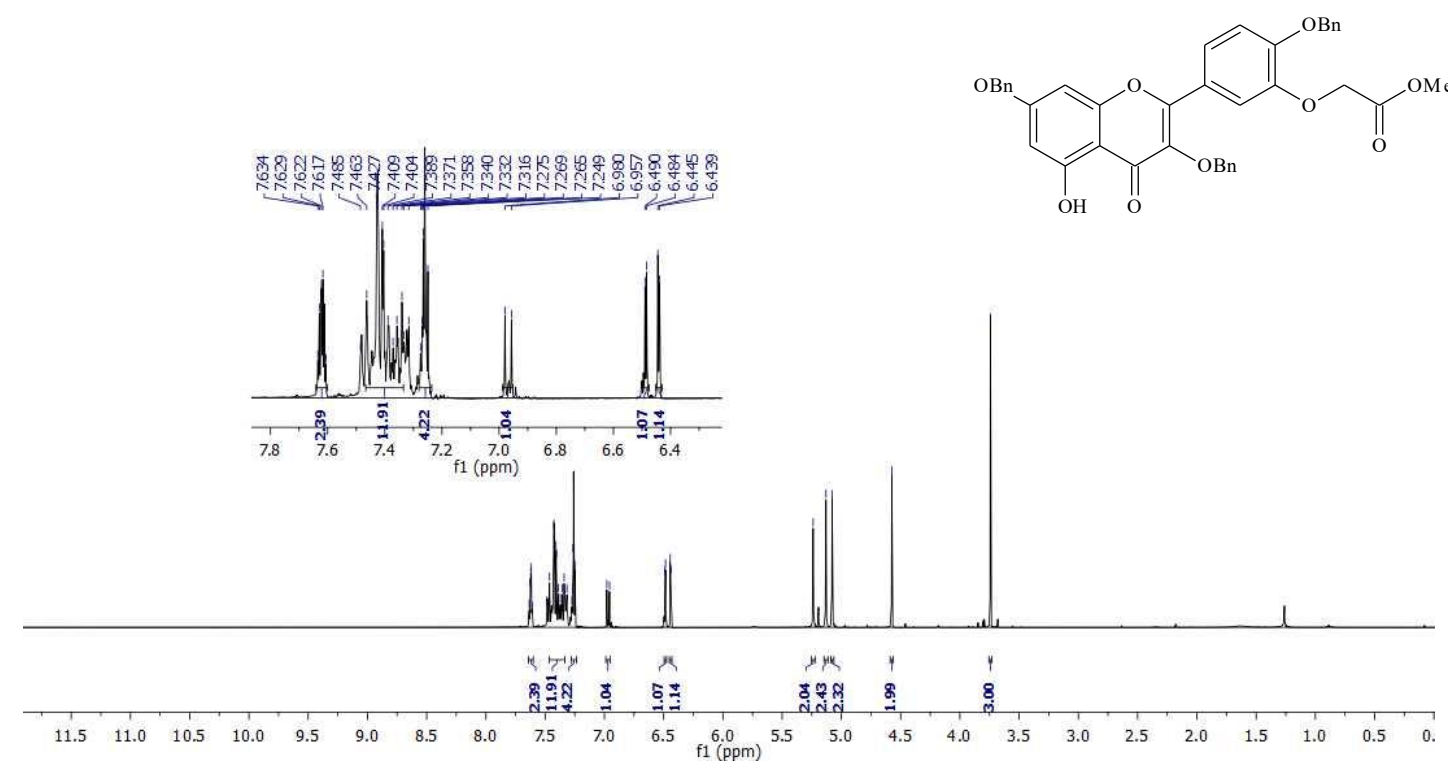

Carbon NMR

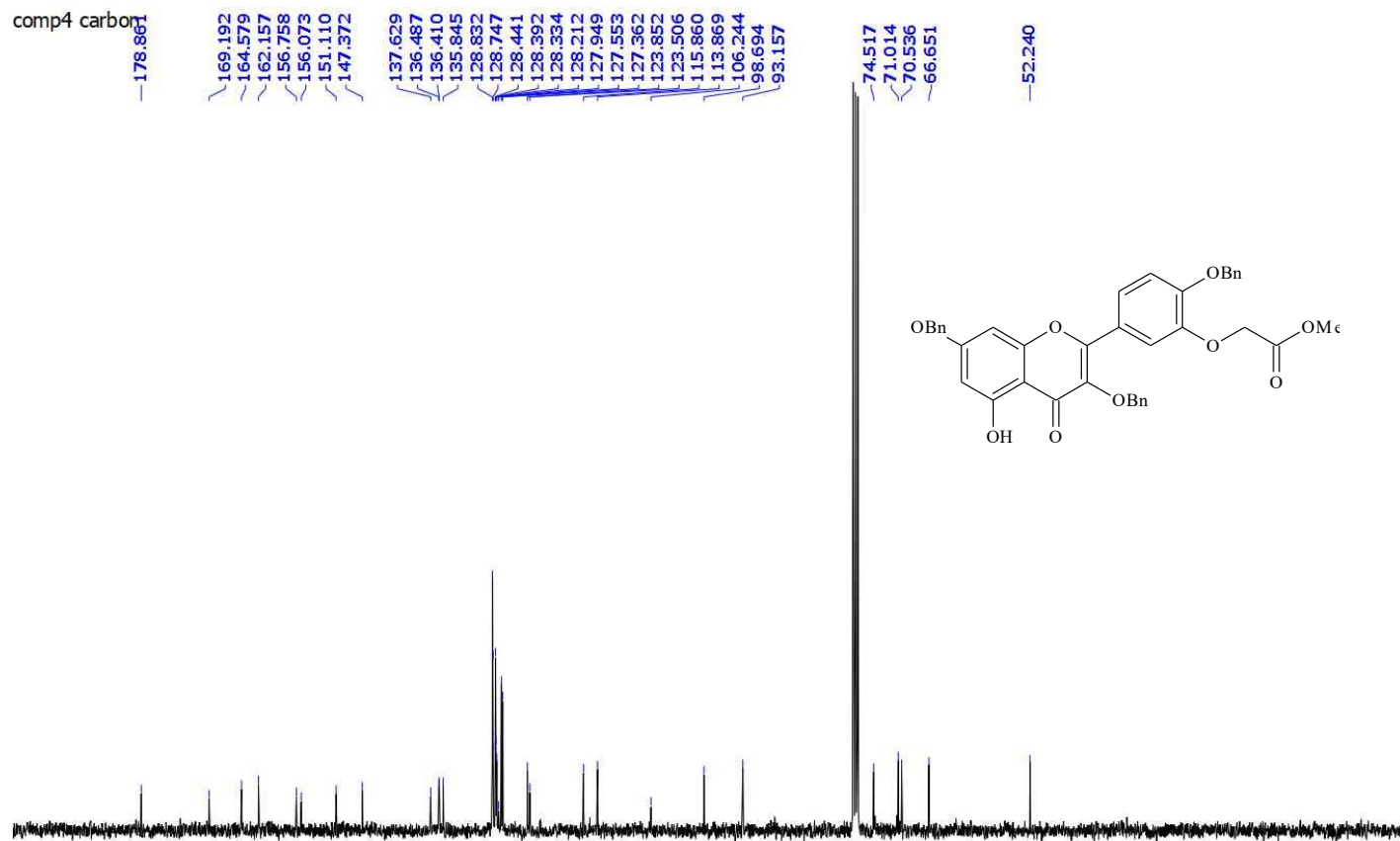

$\begin{array}{llllllllllllllllllll}190 & 180 & 170 & 160 & 150 & 140 & 130 & 120 & 110 & \begin{array}{c}100 \\ 100\end{array} & 90 & 80 & 70 & 60 & 50 & 40 & 30 & 20 & 10 & 0\end{array}$ 
${ }^{1} \mathrm{H}$ NMR and ${ }^{13} \mathrm{C}$ NMR of Compound 5

Proton NMR

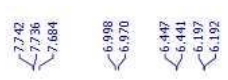

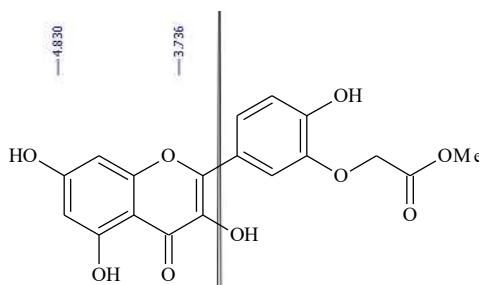

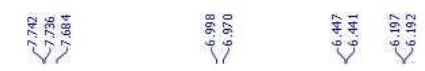
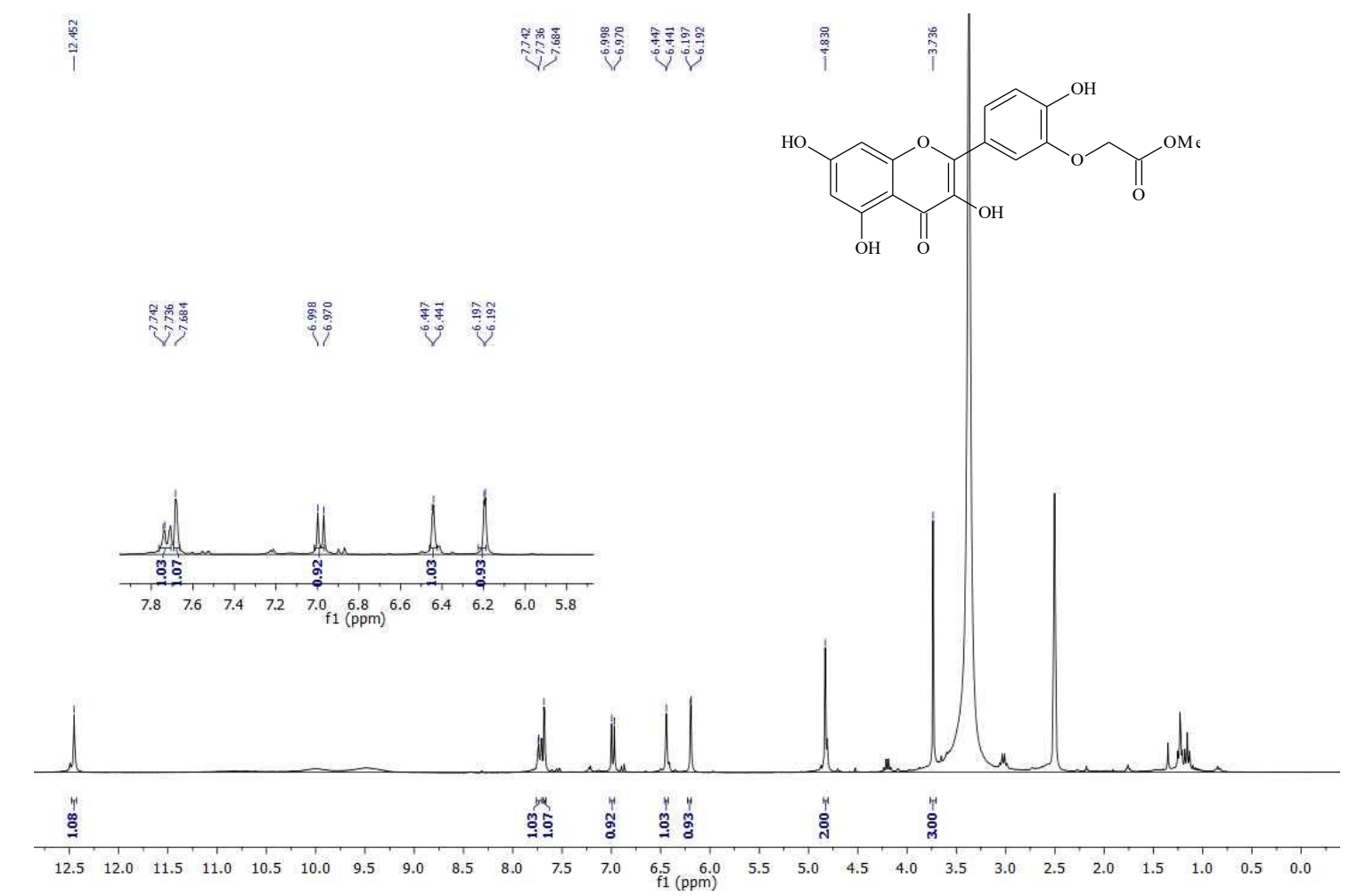

$\mathrm{OH} \mathrm{O}$

Carbon NMR

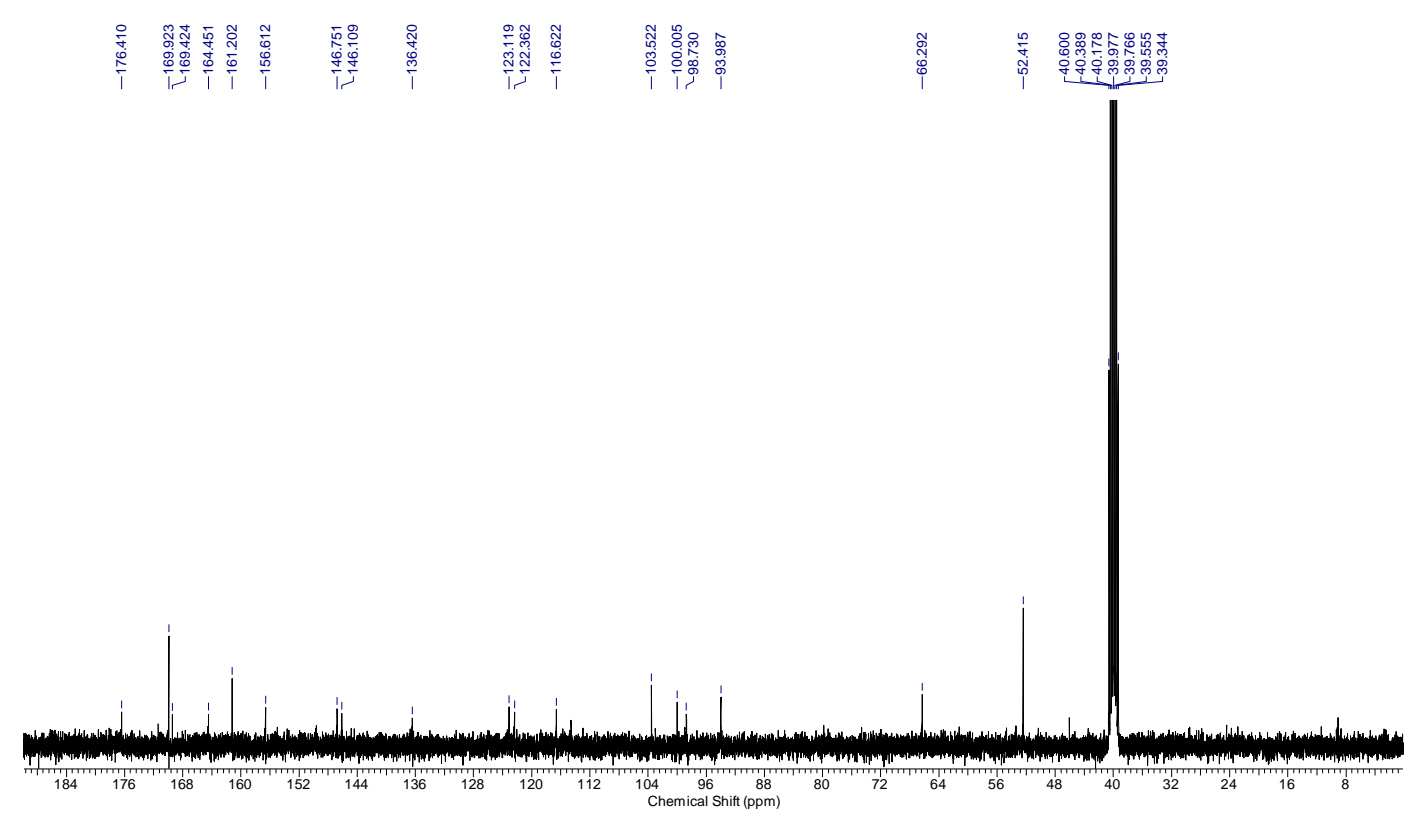




\section{${ }^{1} \mathrm{H}$ NMR and ${ }^{13} \mathrm{C}$ NMR of Compound 6}

Proton NMR

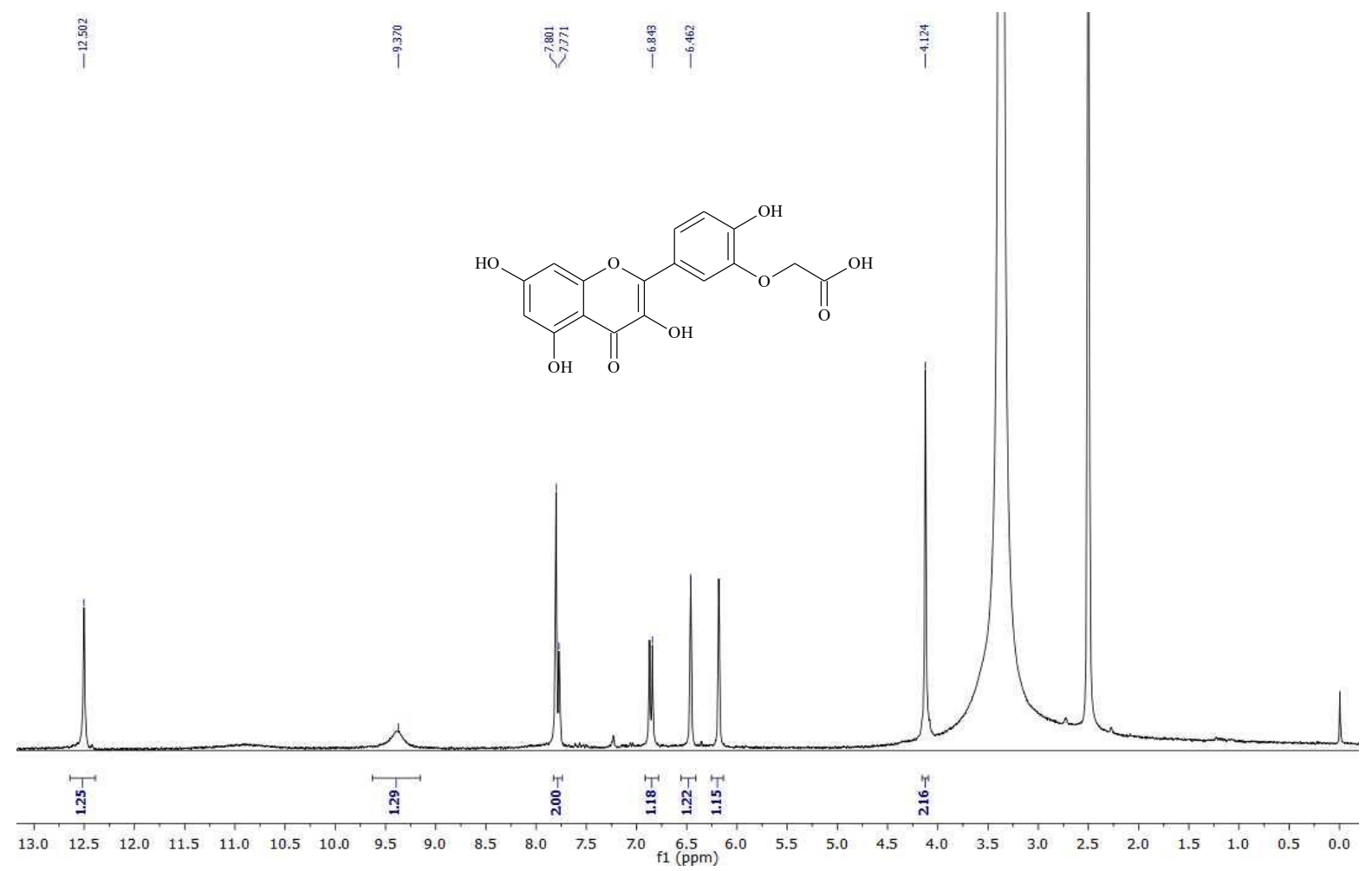

Carbon NMR

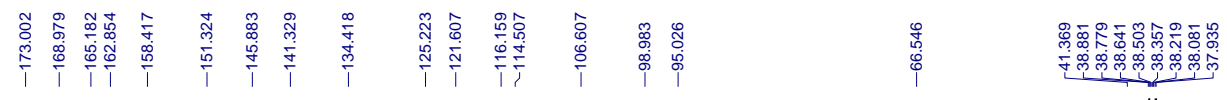

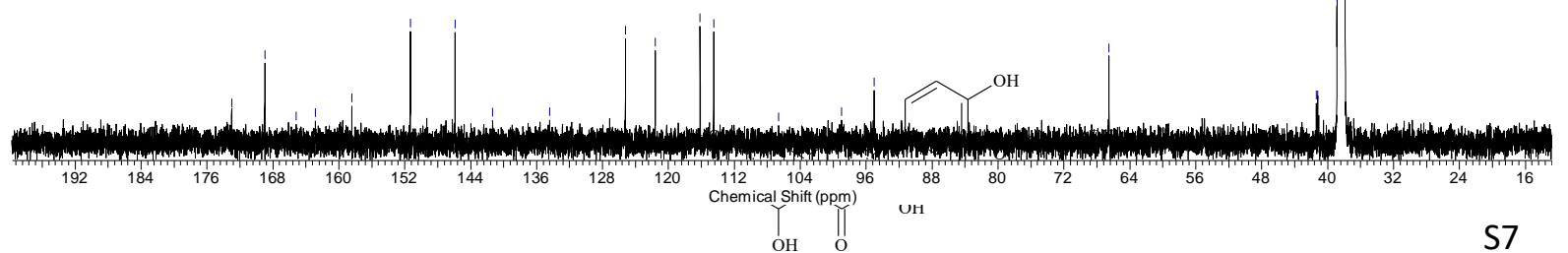


${ }^{1} \mathrm{H}$ NMR and ${ }^{13} \mathrm{C}$ NMR of Compound 7

Proton NMR
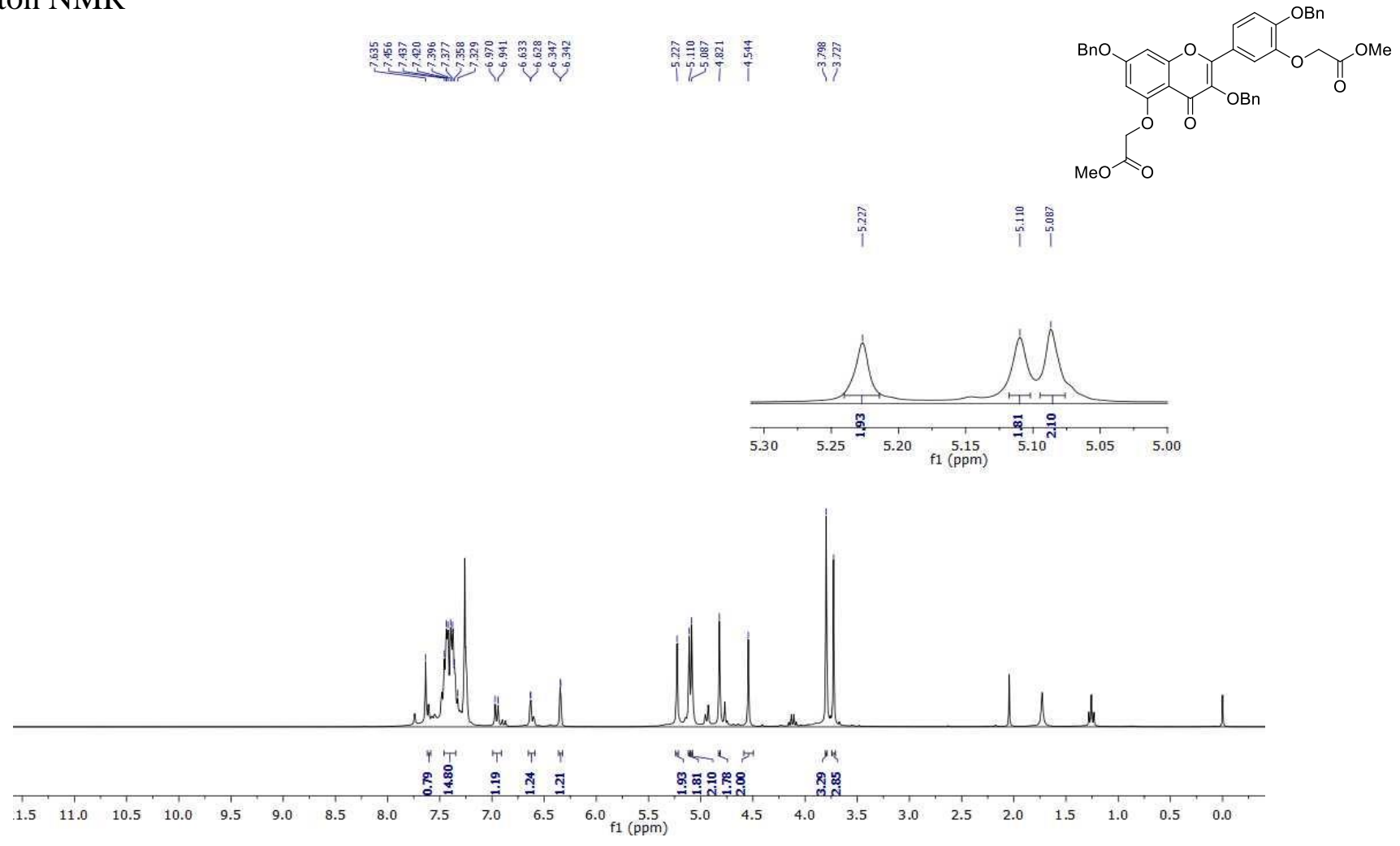

Carbon NMR

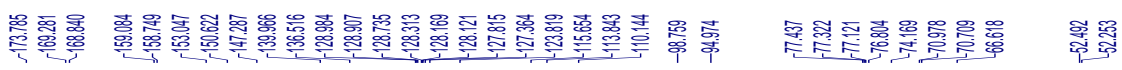

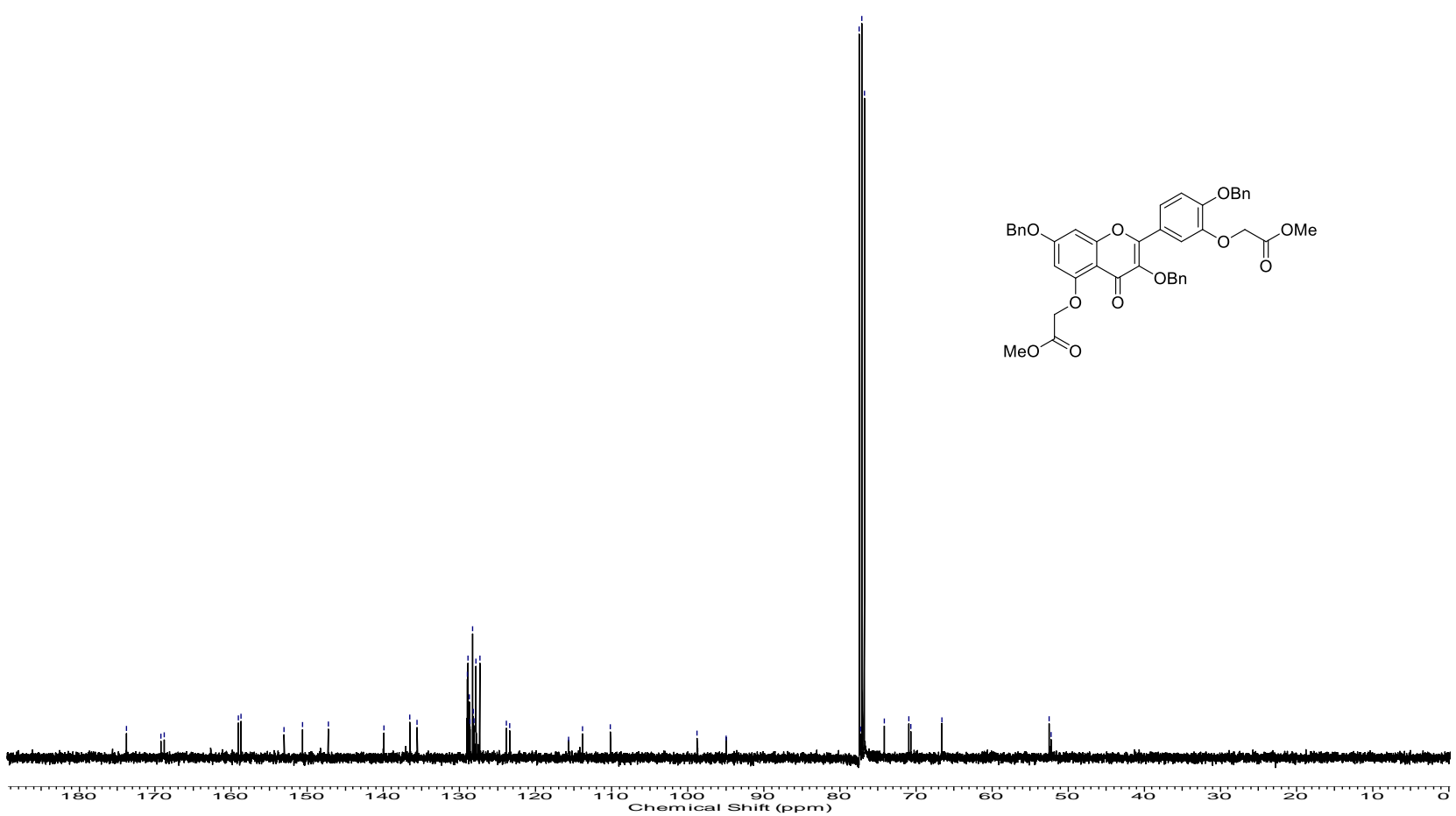


${ }^{1} \mathrm{H}$ NMR and ${ }^{13} \mathrm{C}$ NMR of Compound 8

Proton NMR

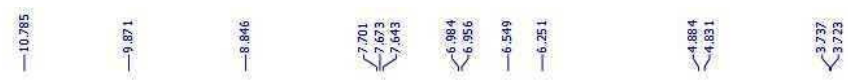
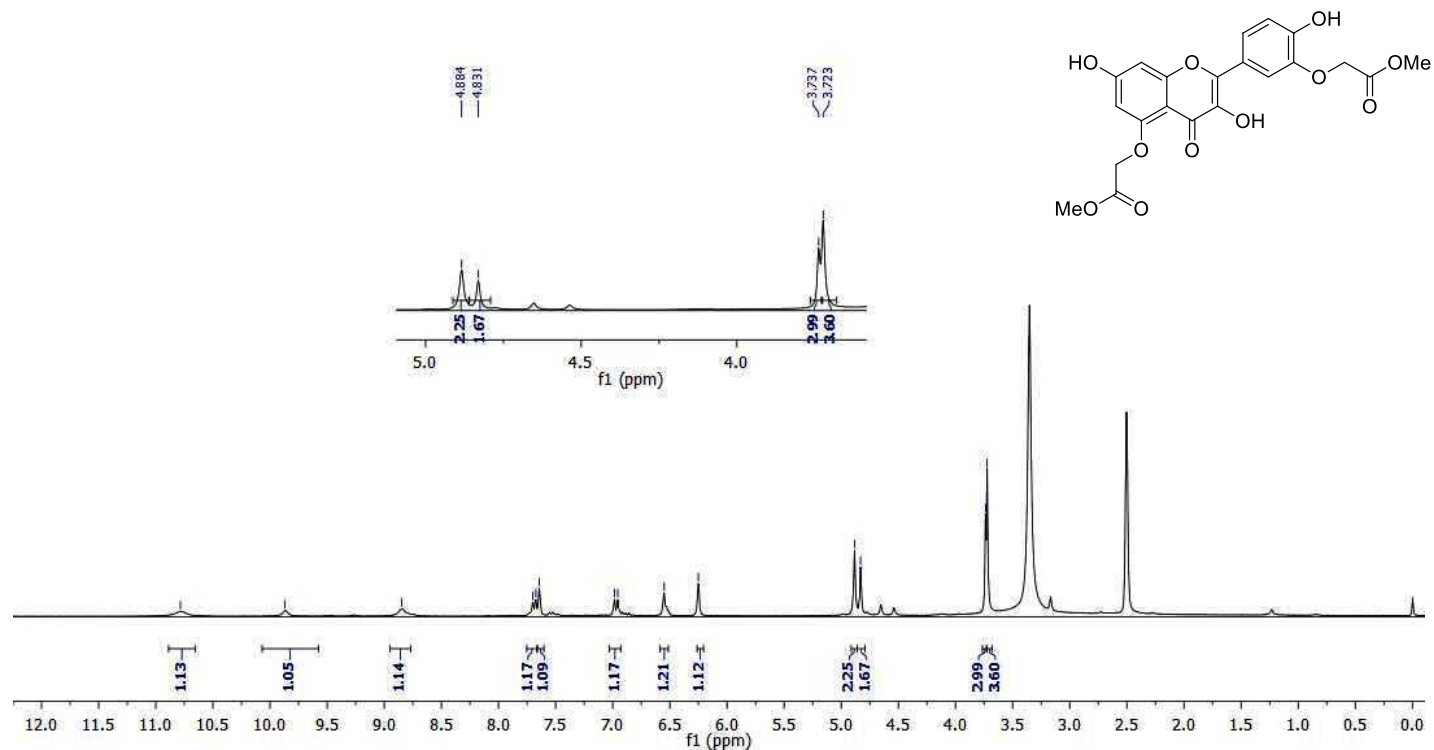

Carbon NMR

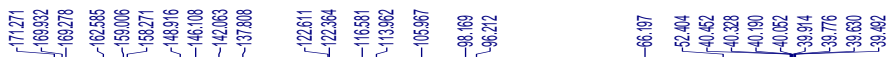
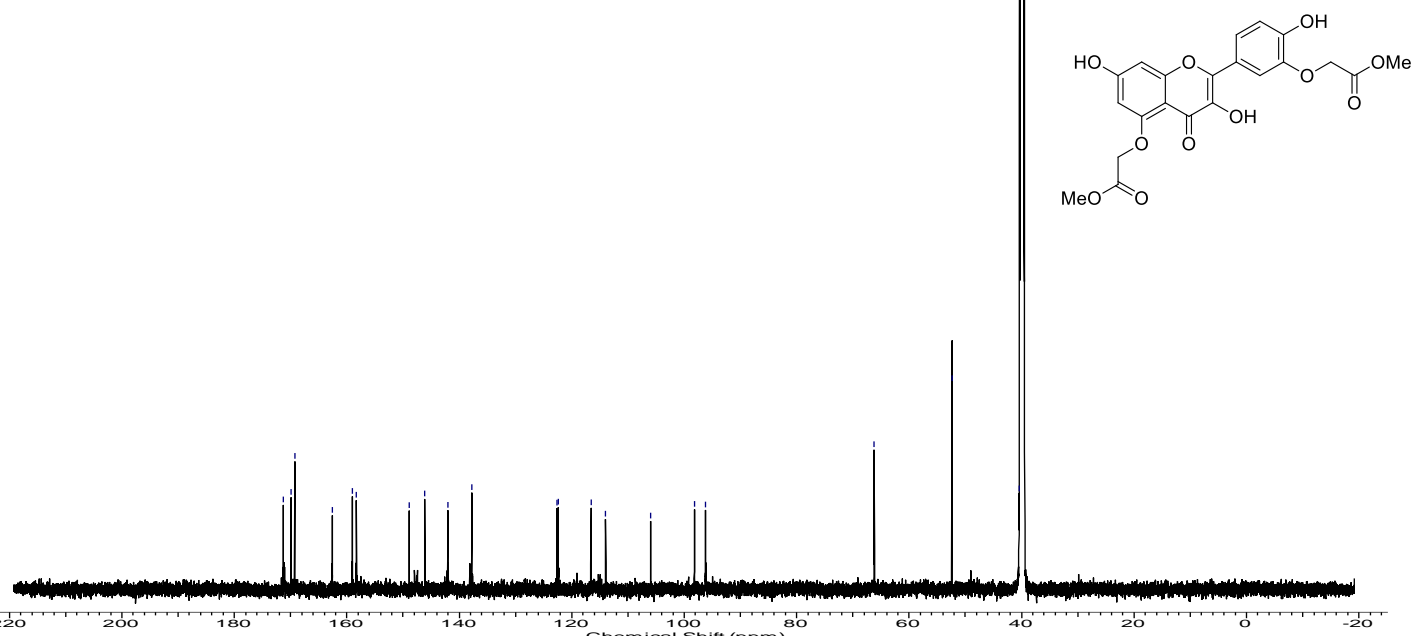
${ }^{1} \mathrm{H}$ NMR and ${ }^{13} \mathrm{C}$ NMR of Compound 9

Proton NMR

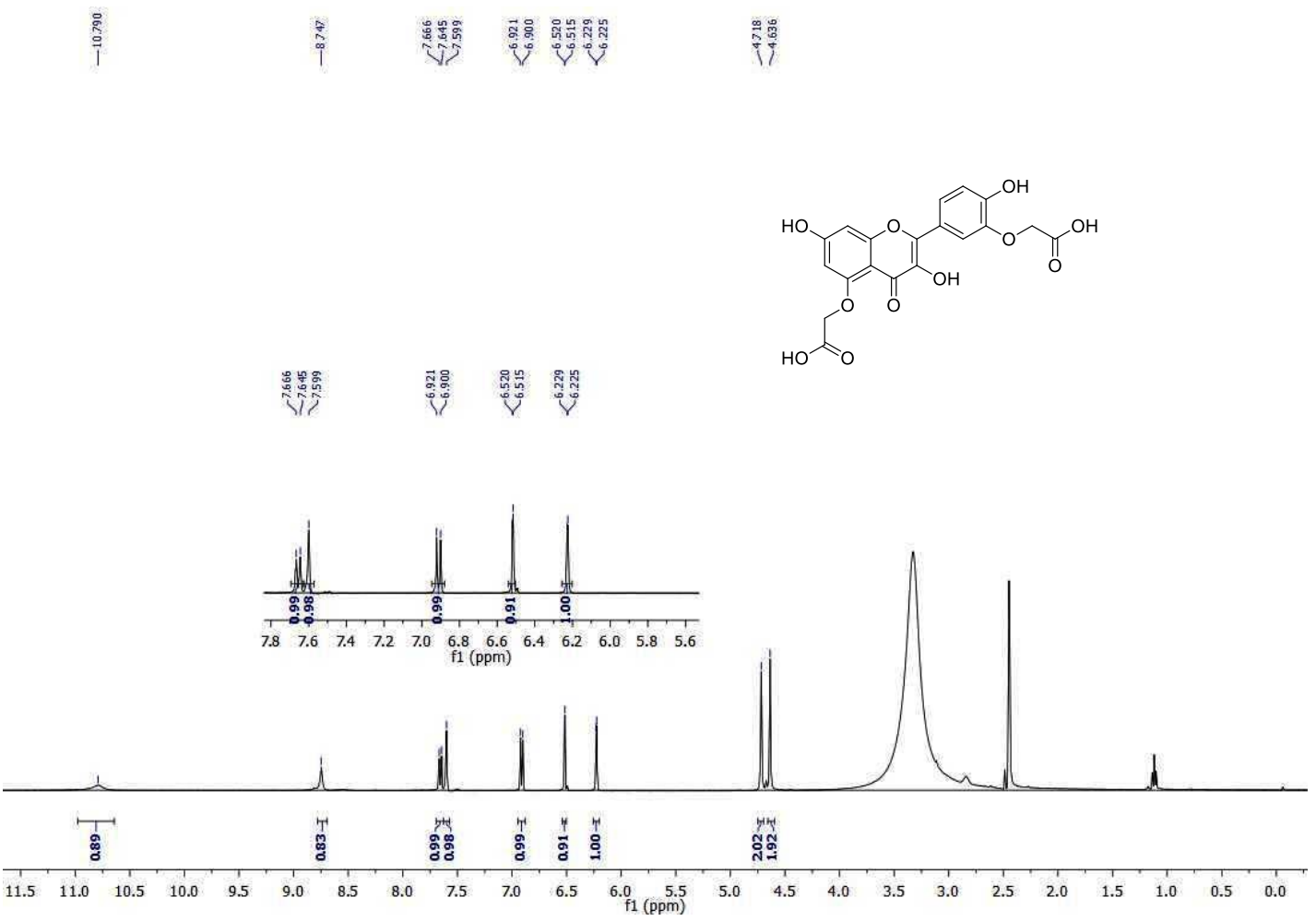

Carbon NMR

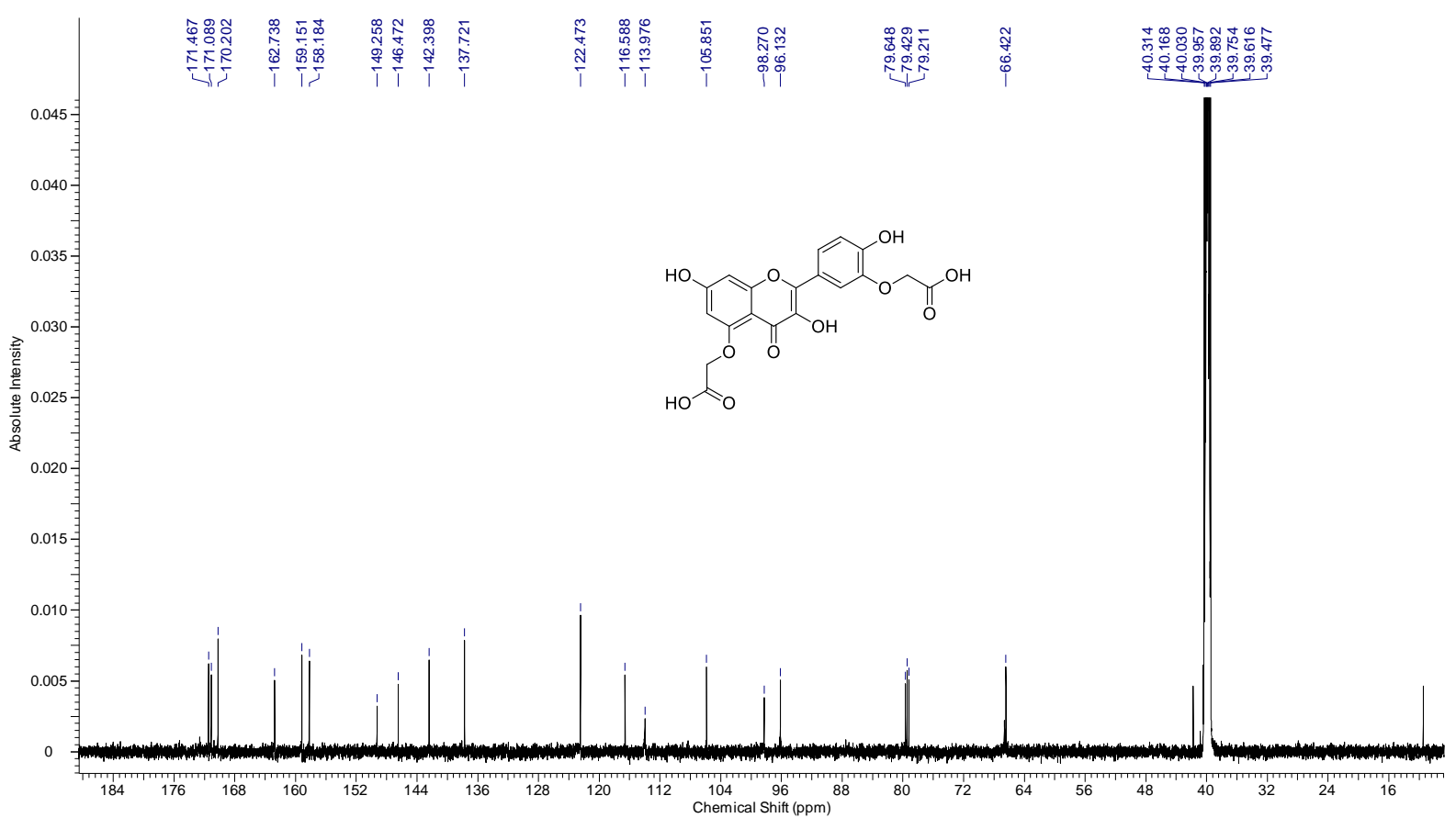


${ }^{1} \mathrm{H}$ NMR and ${ }^{13} \mathrm{C}$ NMR of Compound 10

Proton NMR

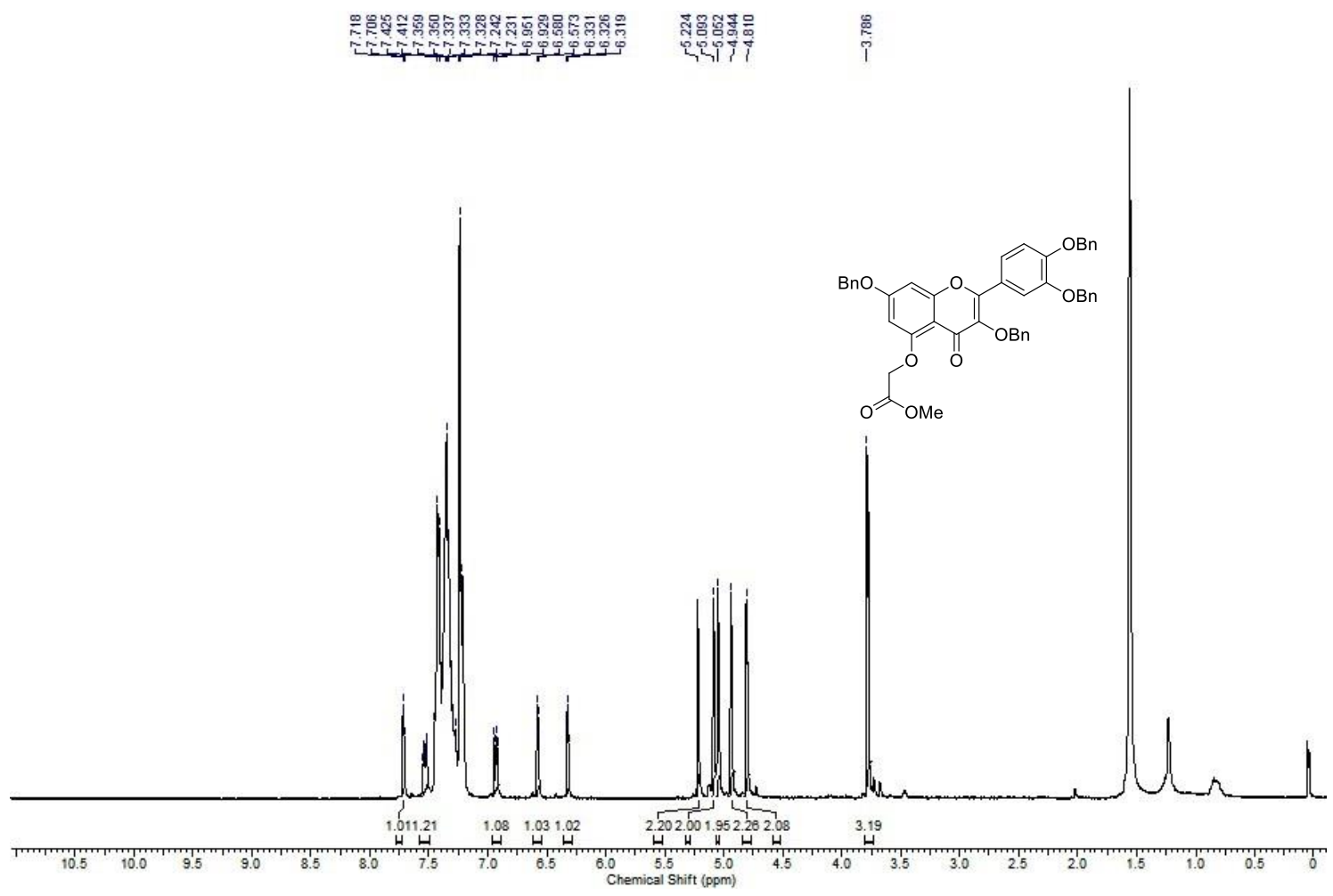

Carbon NMR

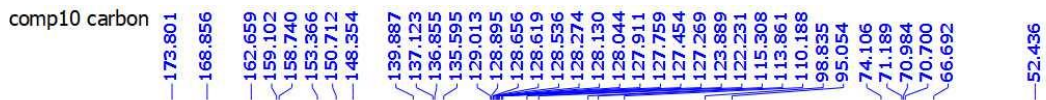

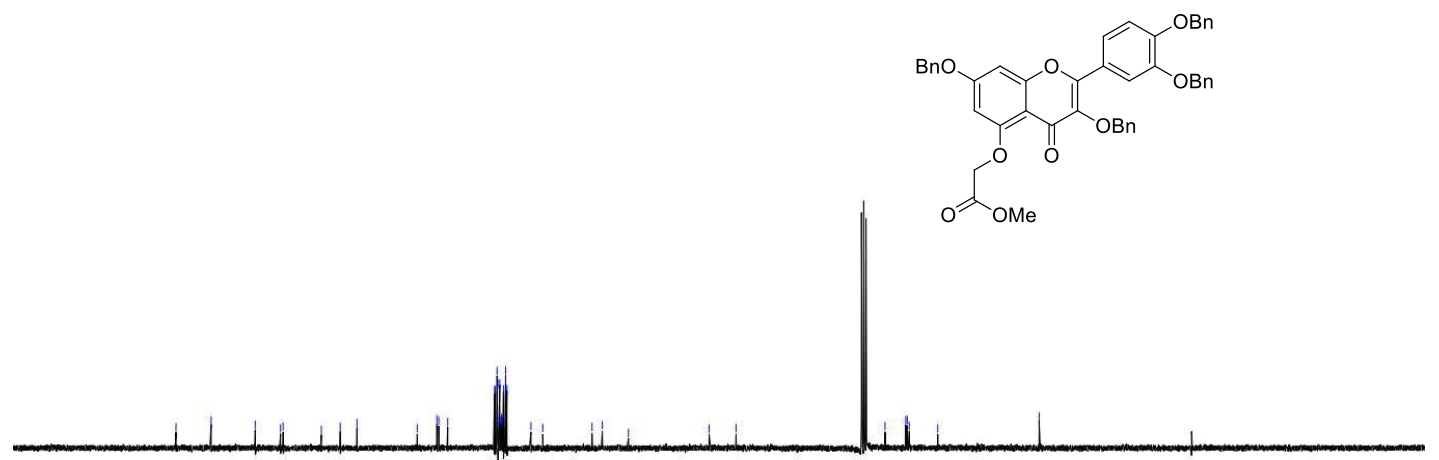

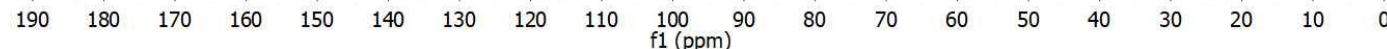


${ }^{1} \mathrm{H}$ NMR and ${ }^{13} \mathrm{C}$ NMR of Compound 11

Proton NMR

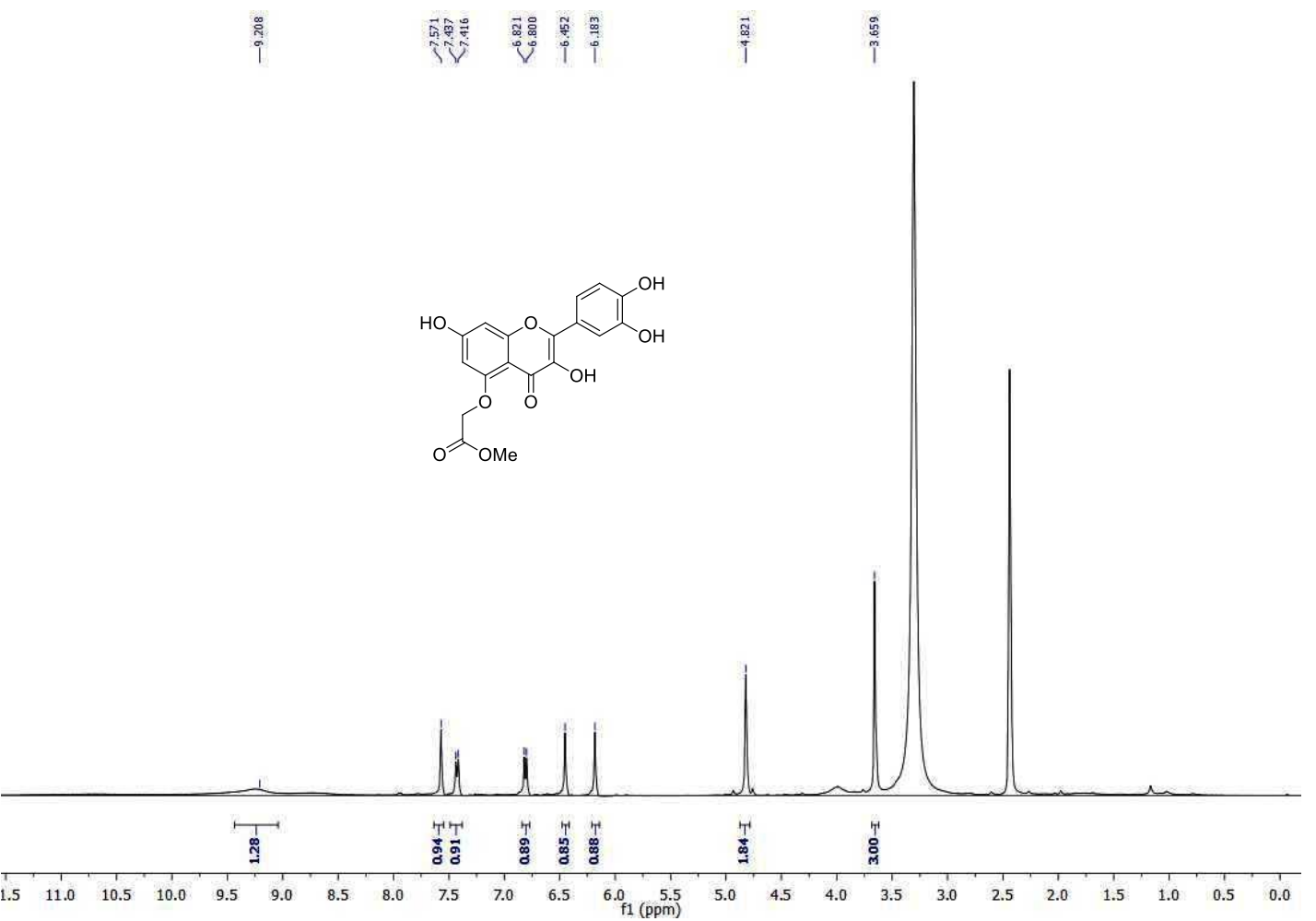

Carbon NMR

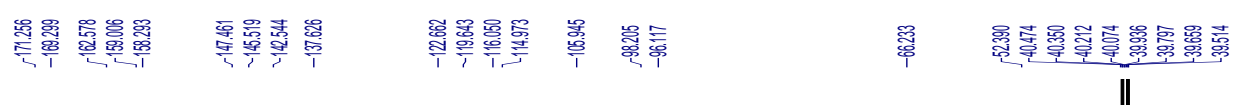

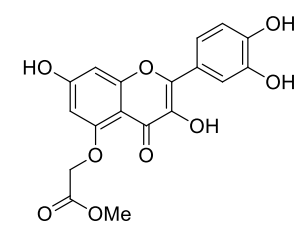


${ }^{1} \mathrm{H}$ NMR and ${ }^{13} \mathrm{C}$ NMR of Compound 12

Proton NMR

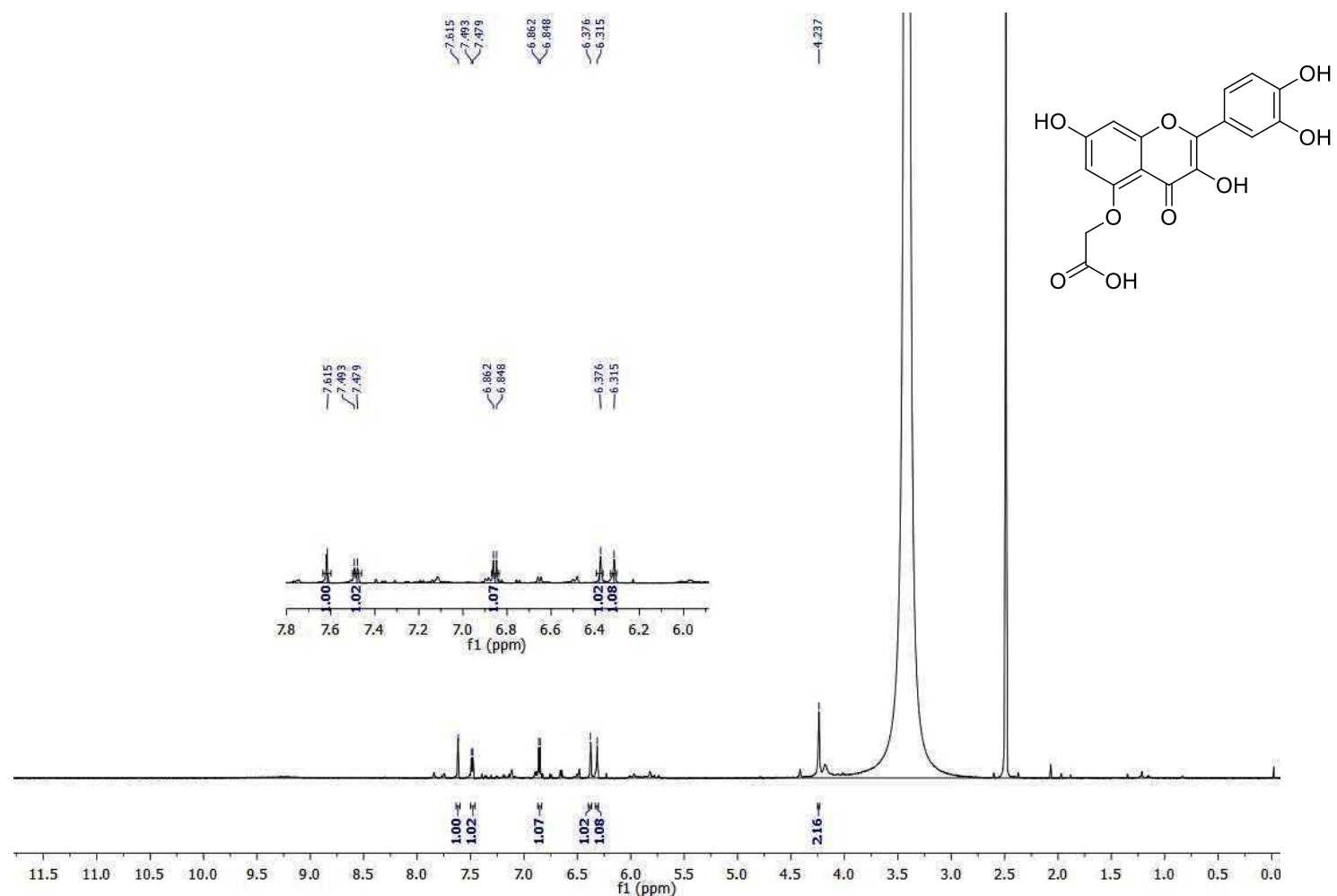

Carbon NMR

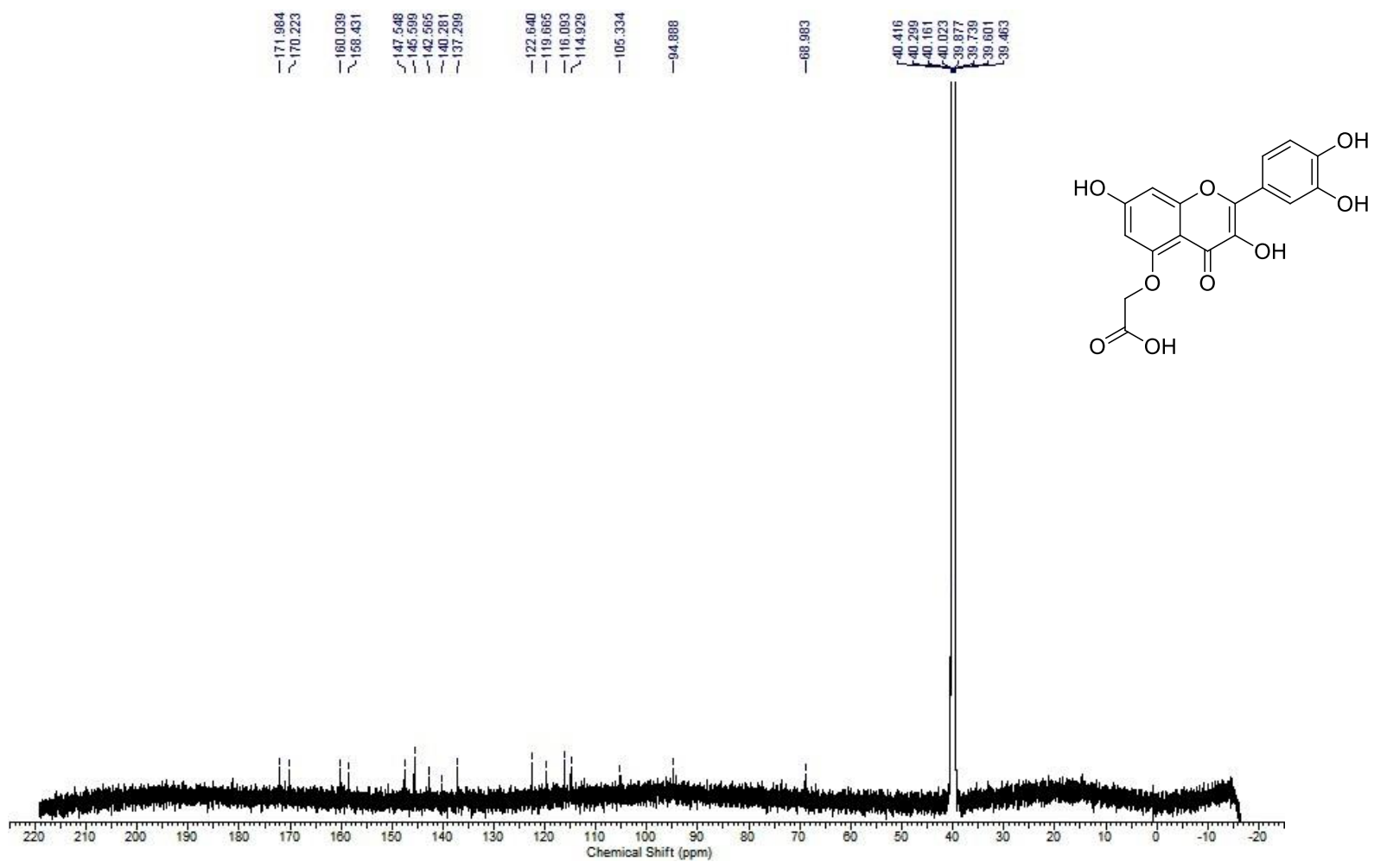


${ }^{1} \mathrm{H}$ NMR and ${ }^{13} \mathrm{C}$ NMR of Compound 13

Proton NMR

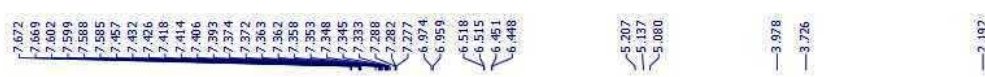
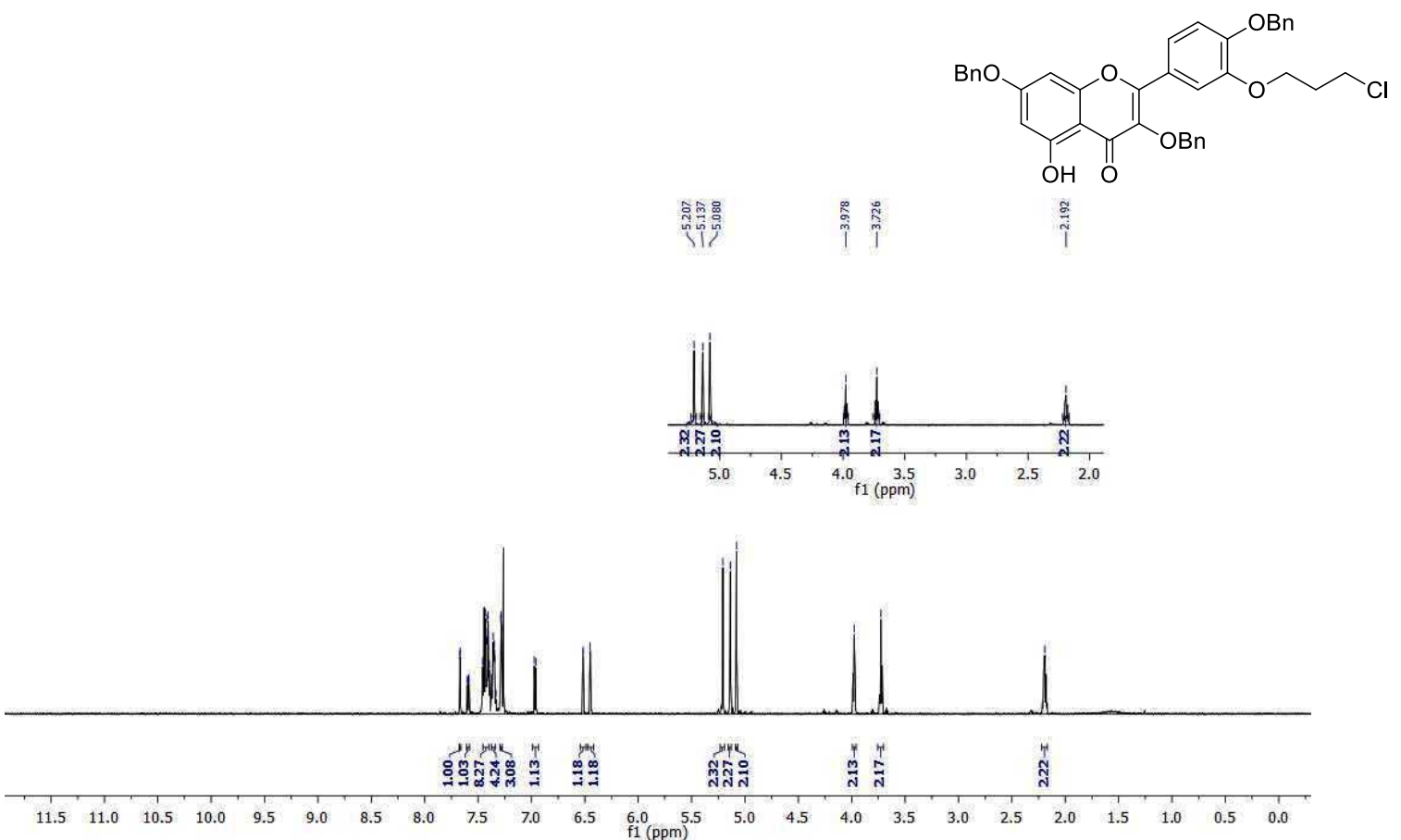

Carbon NMR

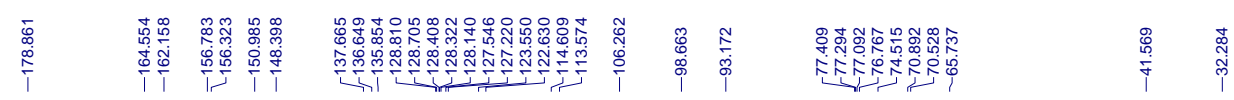

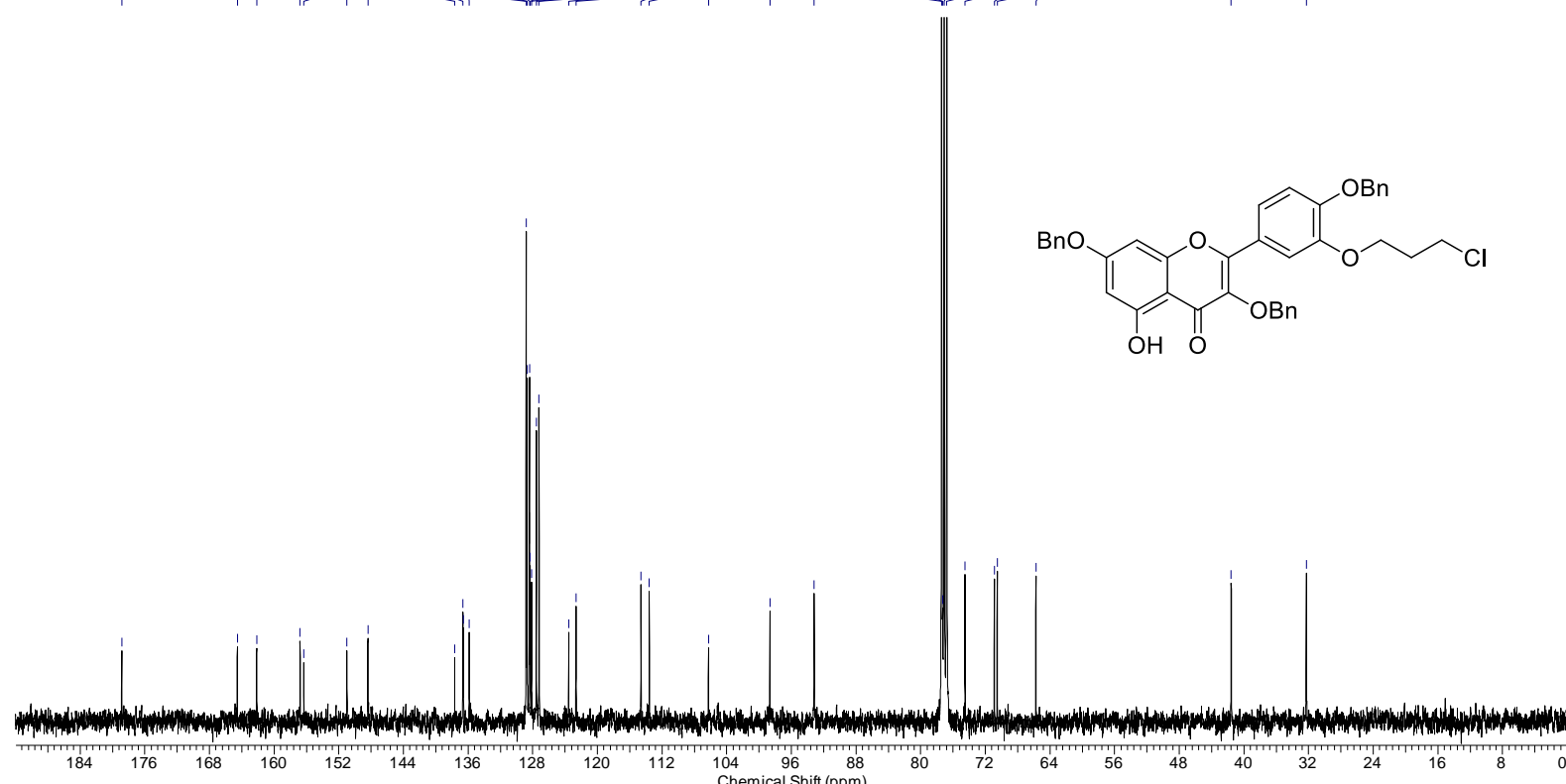


${ }^{1} \mathrm{H}$ NMR and ${ }^{13} \mathrm{C}$ NMR of Compound 14

Proton NMR
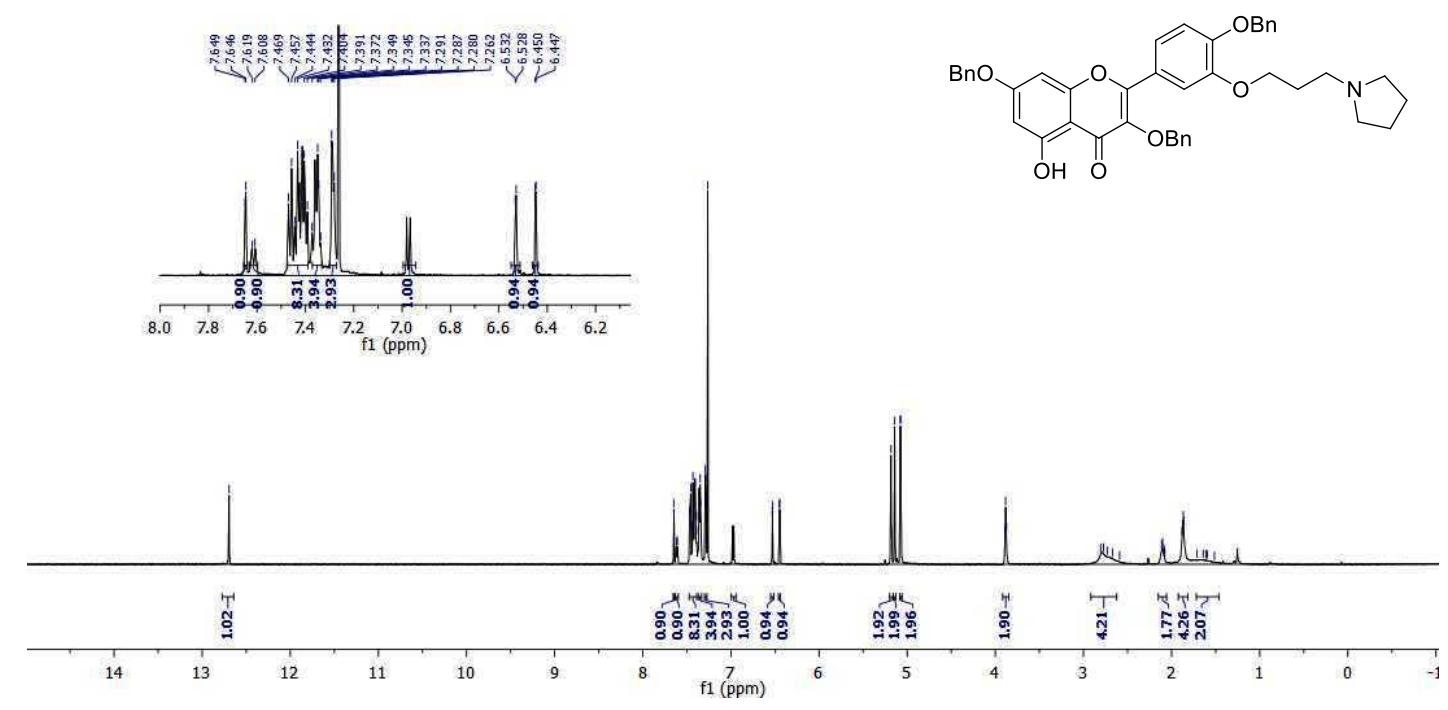

Carbon NMR

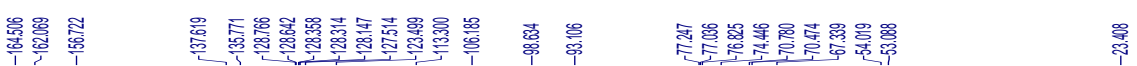

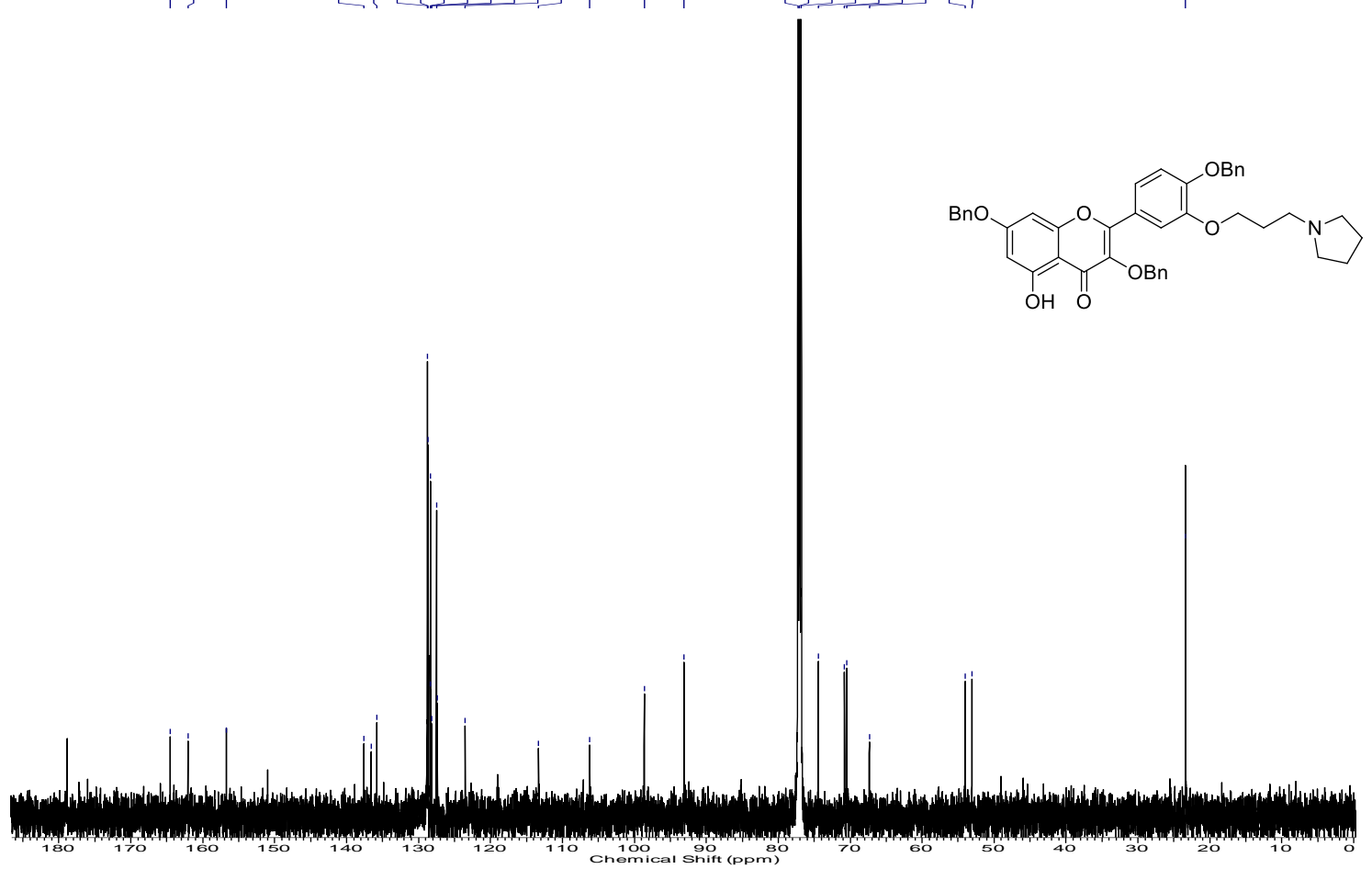


${ }^{1} \mathrm{H}$ NMR and ${ }^{13} \mathrm{C}$ NMR of Compound 15

Proton NMR
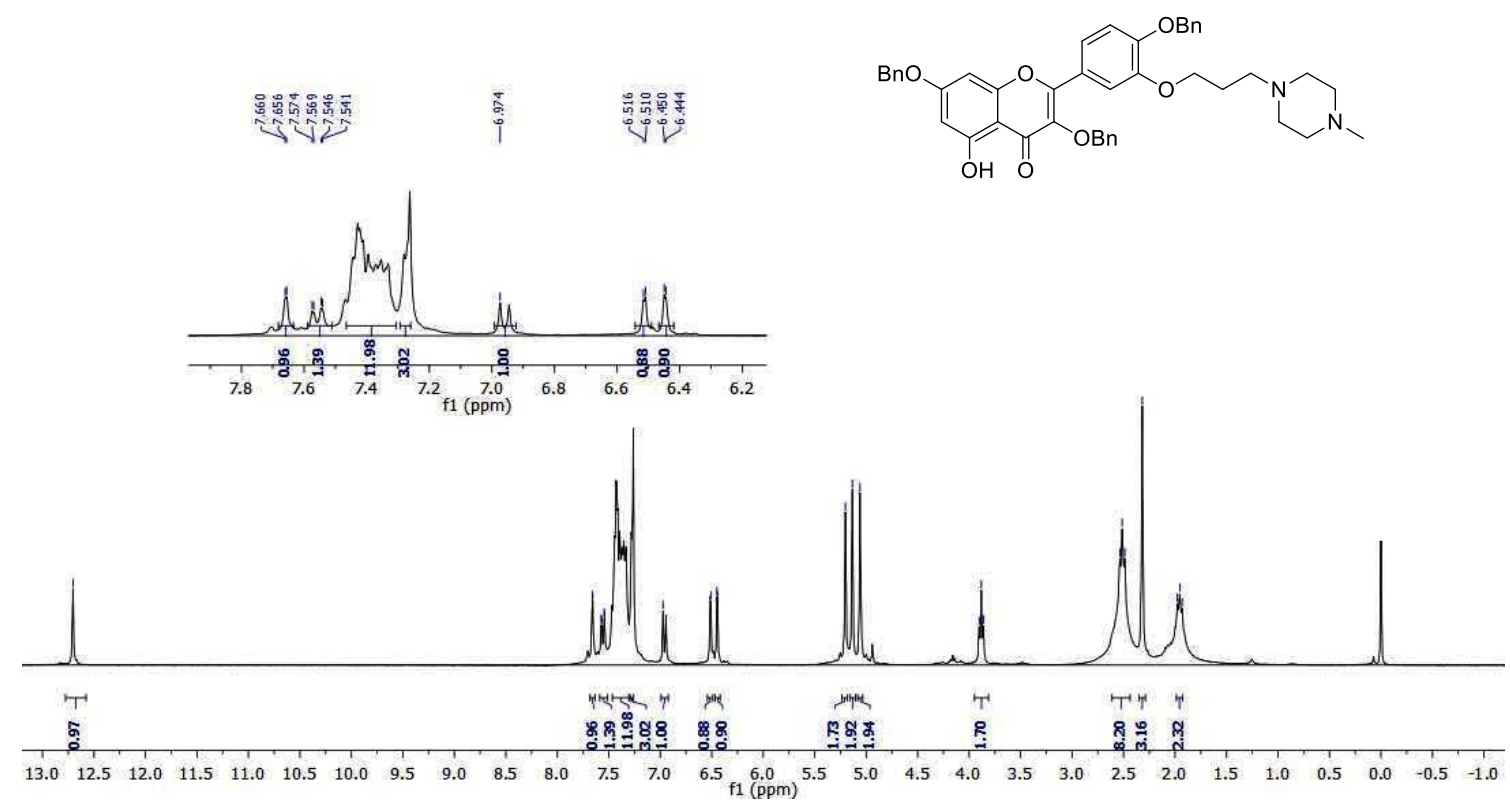

Carbon NMR

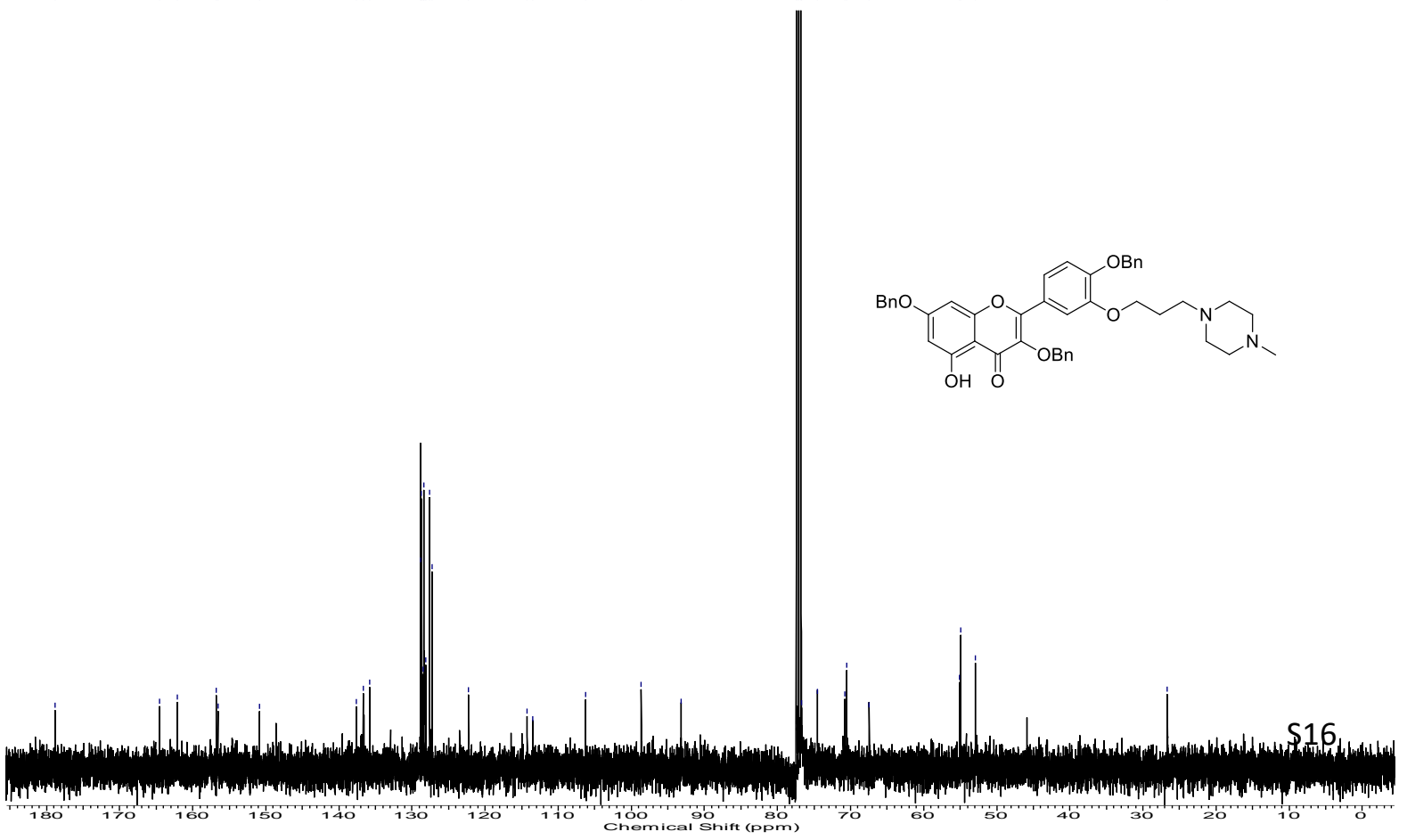




\section{${ }^{1} \mathrm{H}$ NMR and ${ }^{13} \mathrm{C}$ NMR of Compound 16}

Proton NMR

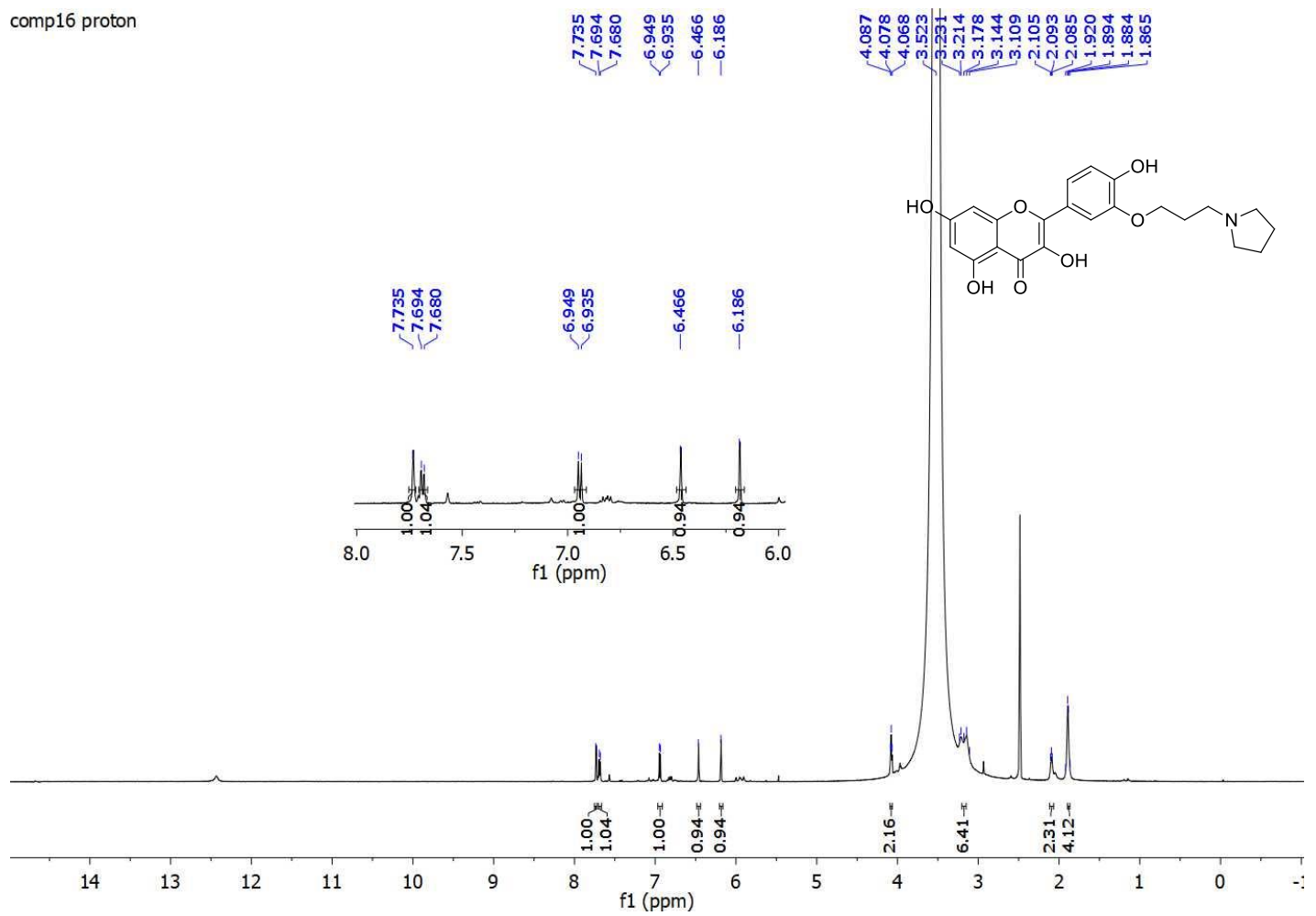

Carbon NMR

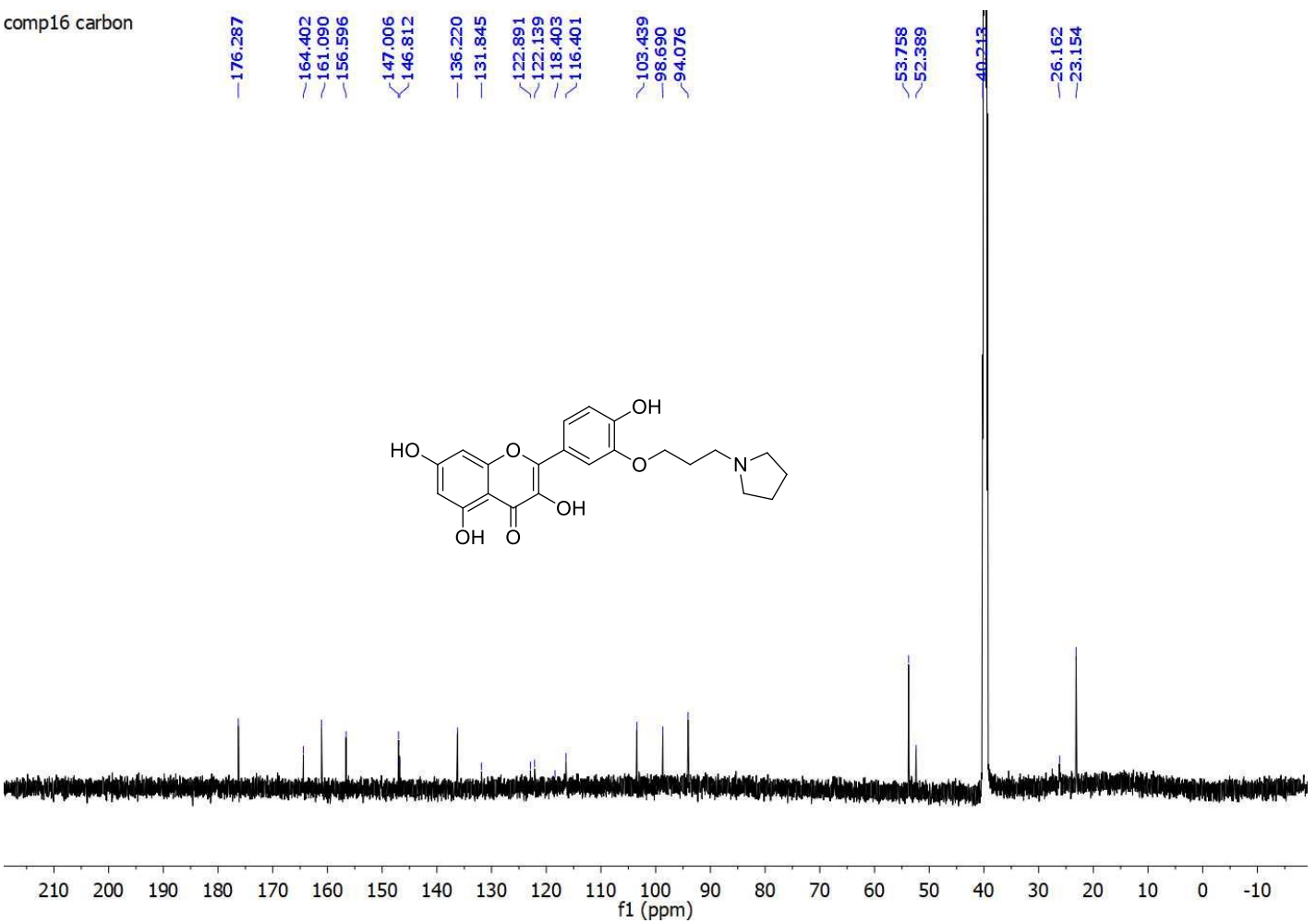


${ }^{1} \mathrm{H}$ NMR and ${ }^{13} \mathrm{C}$ NMR of Compound 17

Proton NMR

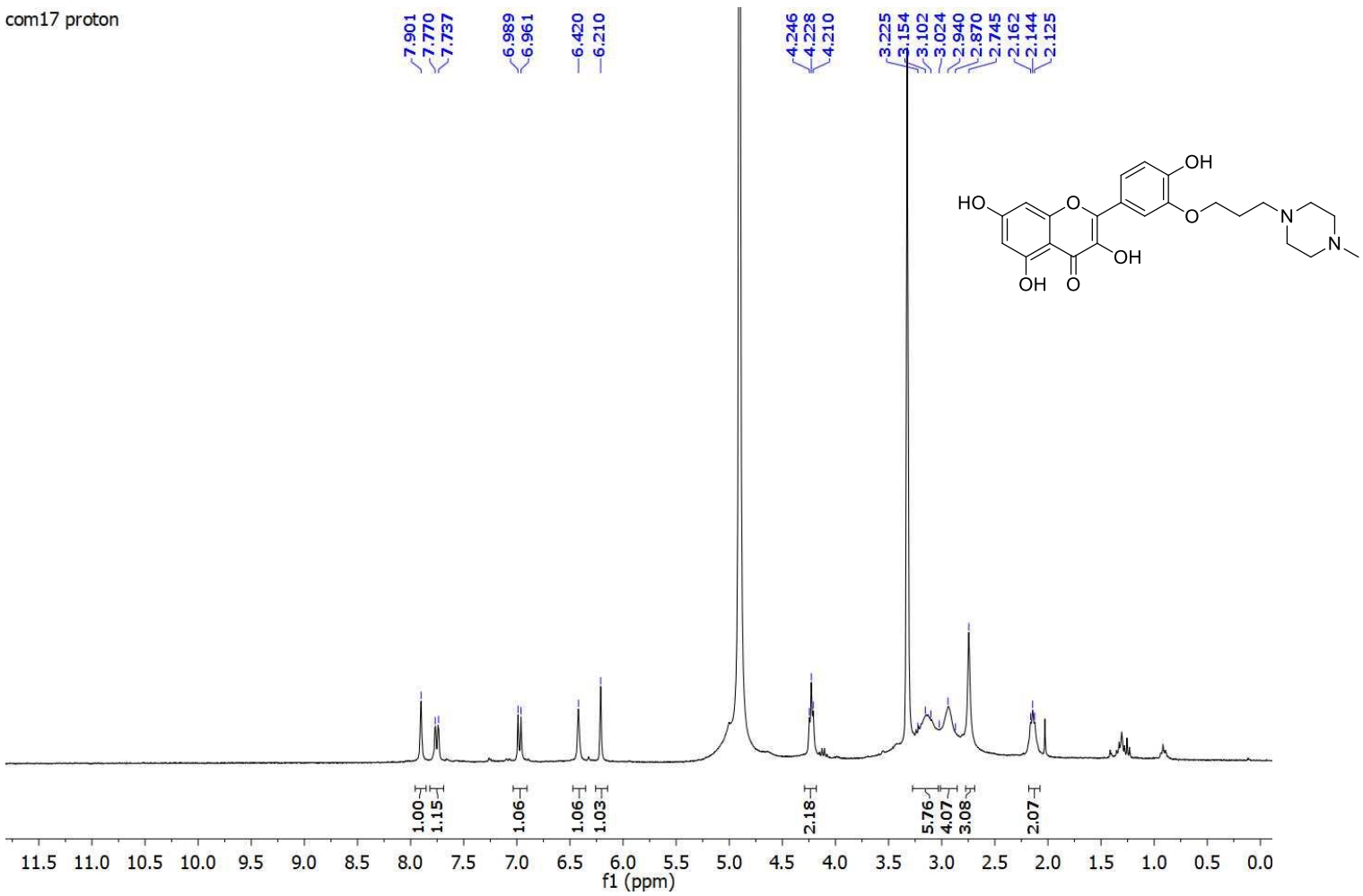

Carbon NMR

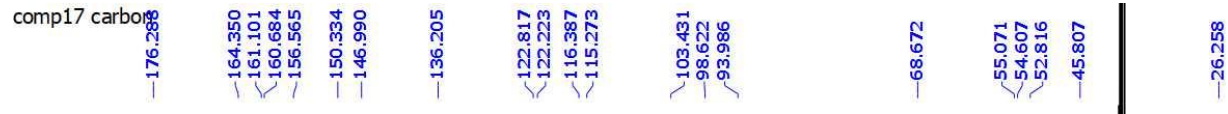<smiles>CN1CCN(CCCOc2cc(-c3oc4cc(O)cc(O)c4c(=O)c3O)ccc2O)CC1</smiles>

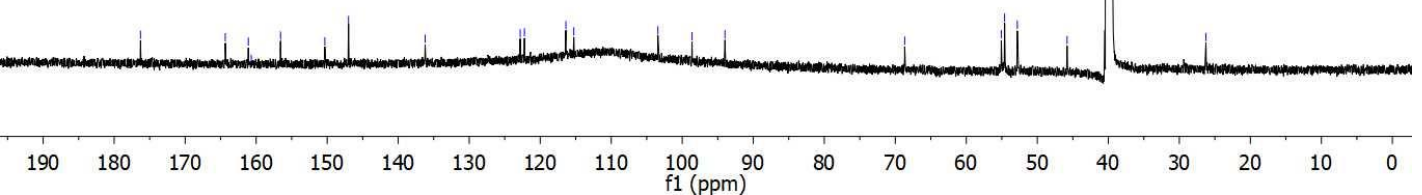




\section{${ }^{1} \mathrm{H}$ NMR and ${ }^{13} \mathrm{C}$ NMR of Compound 18}

Proton NMR

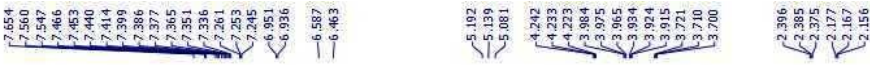
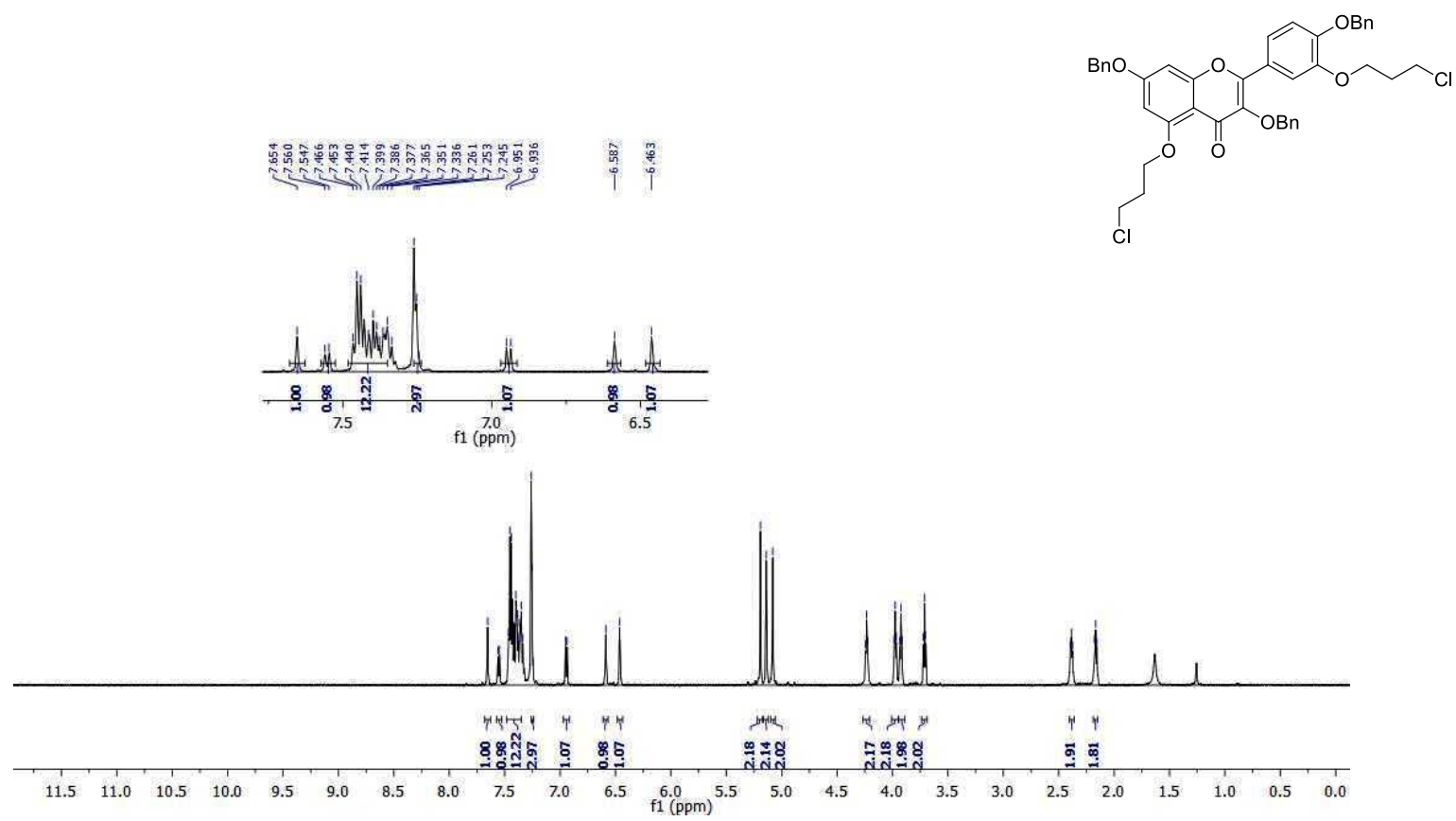

Carbon NMR

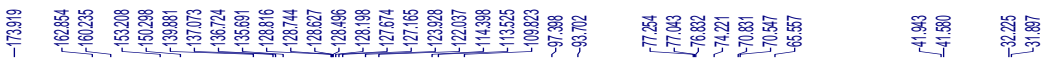

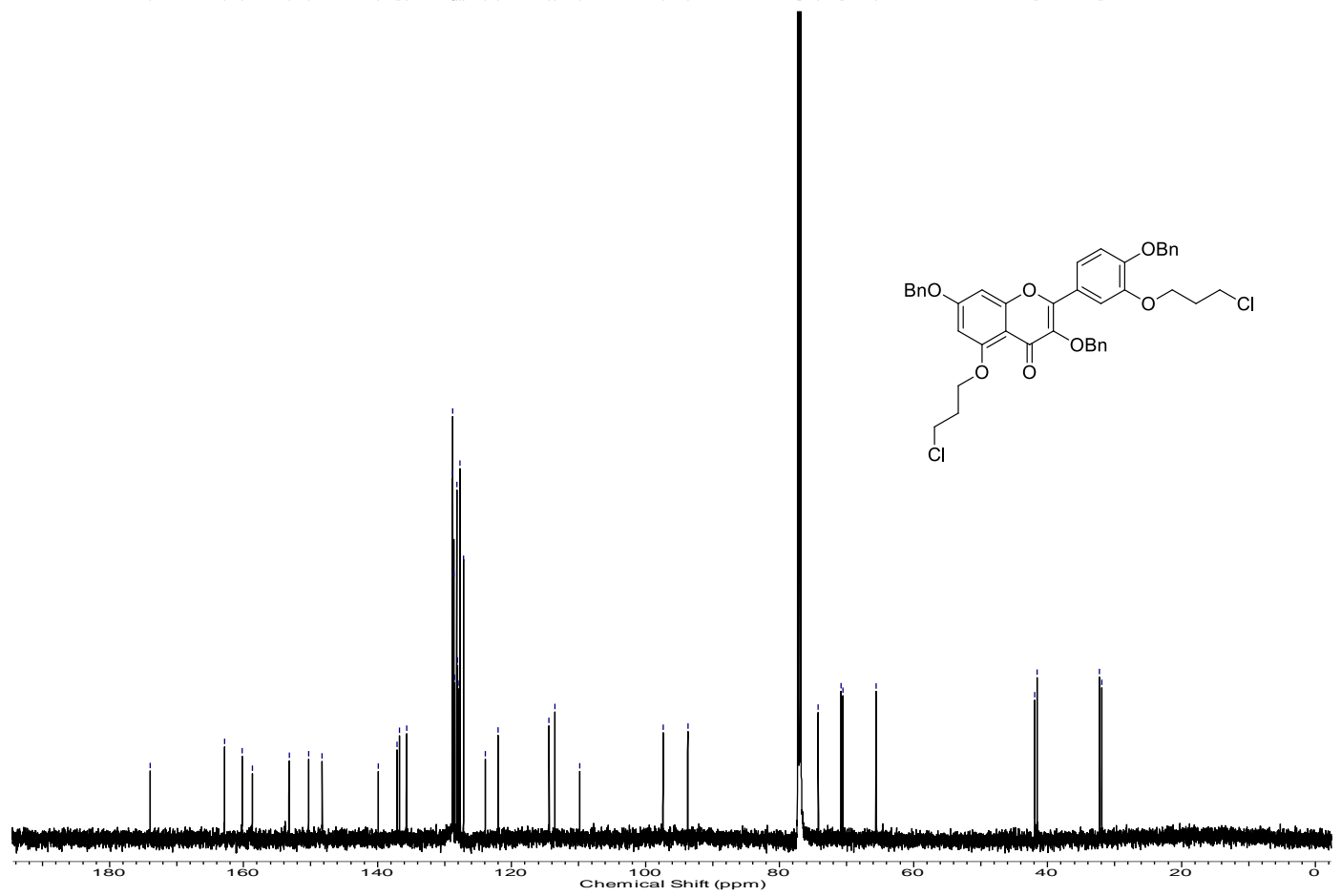


${ }^{1} \mathrm{H}$ NMR and ${ }^{13} \mathrm{C}$ NMR of Compound 19

Proton NMR

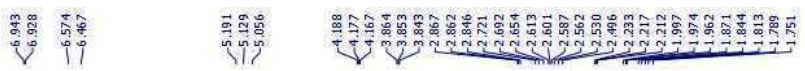

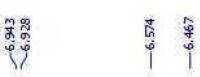
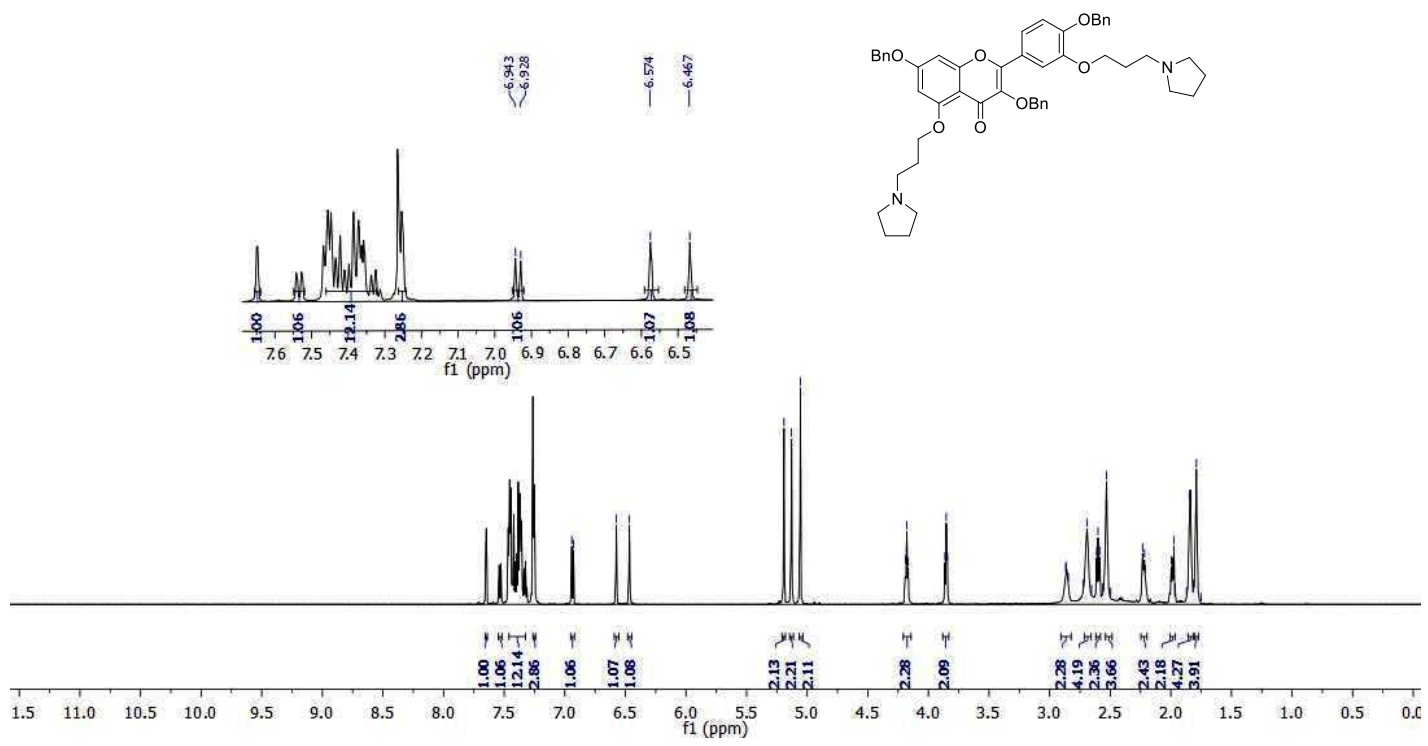

Carbon NMR

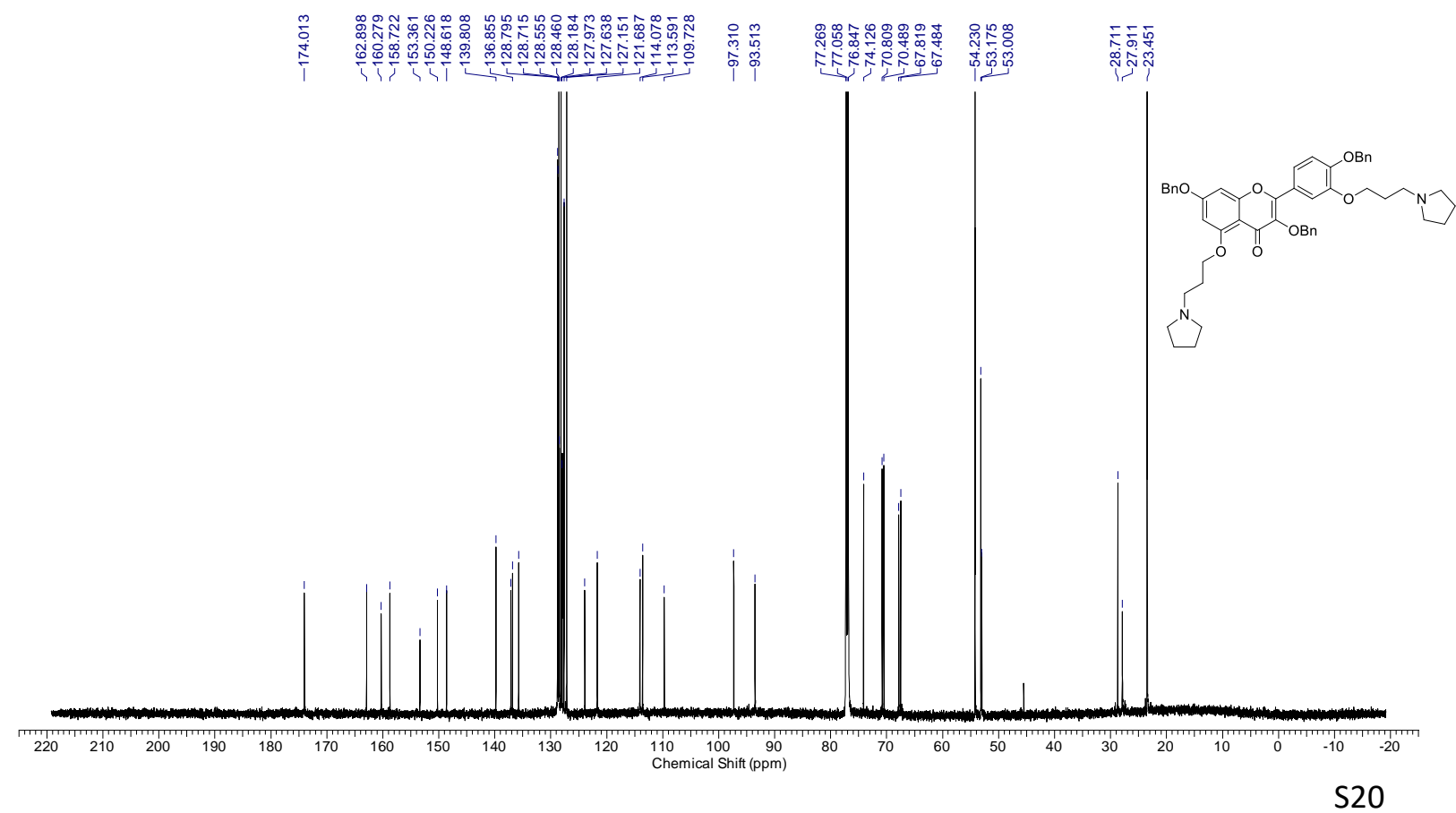


${ }^{1} \mathrm{H}$ NMR and ${ }^{13} \mathrm{C}$ NMR of Compound 20

Proton NMR

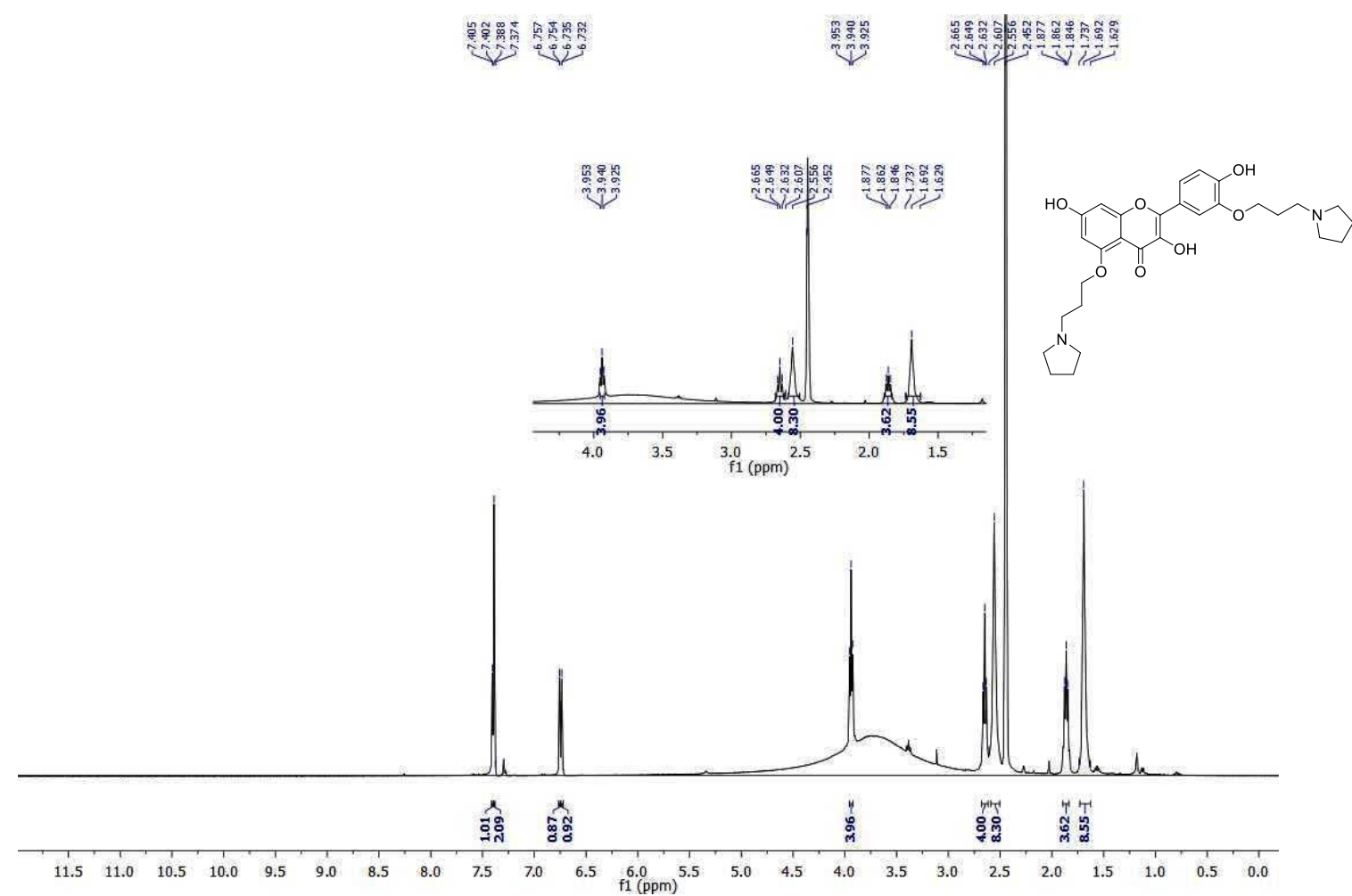

Carbon NMR

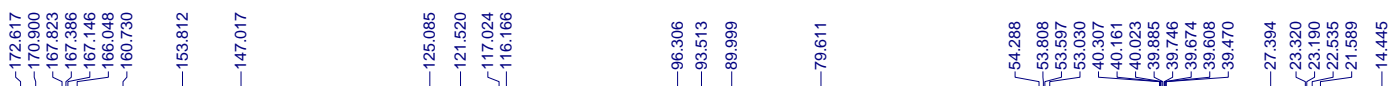

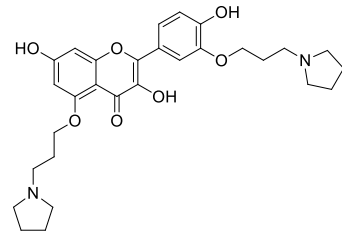

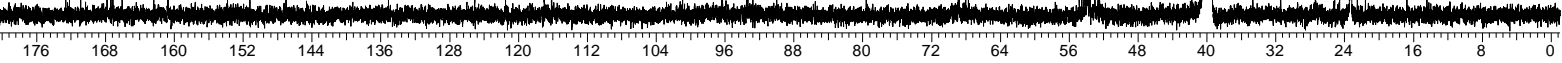

Chemical Shift (ppm) 
${ }^{1} \mathrm{H}$ NMR and ${ }^{13} \mathrm{C}$ NMR of Compound 21

Proton NMR

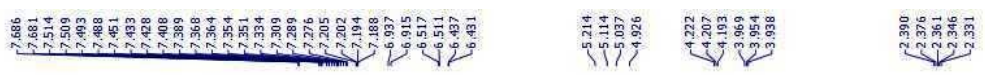
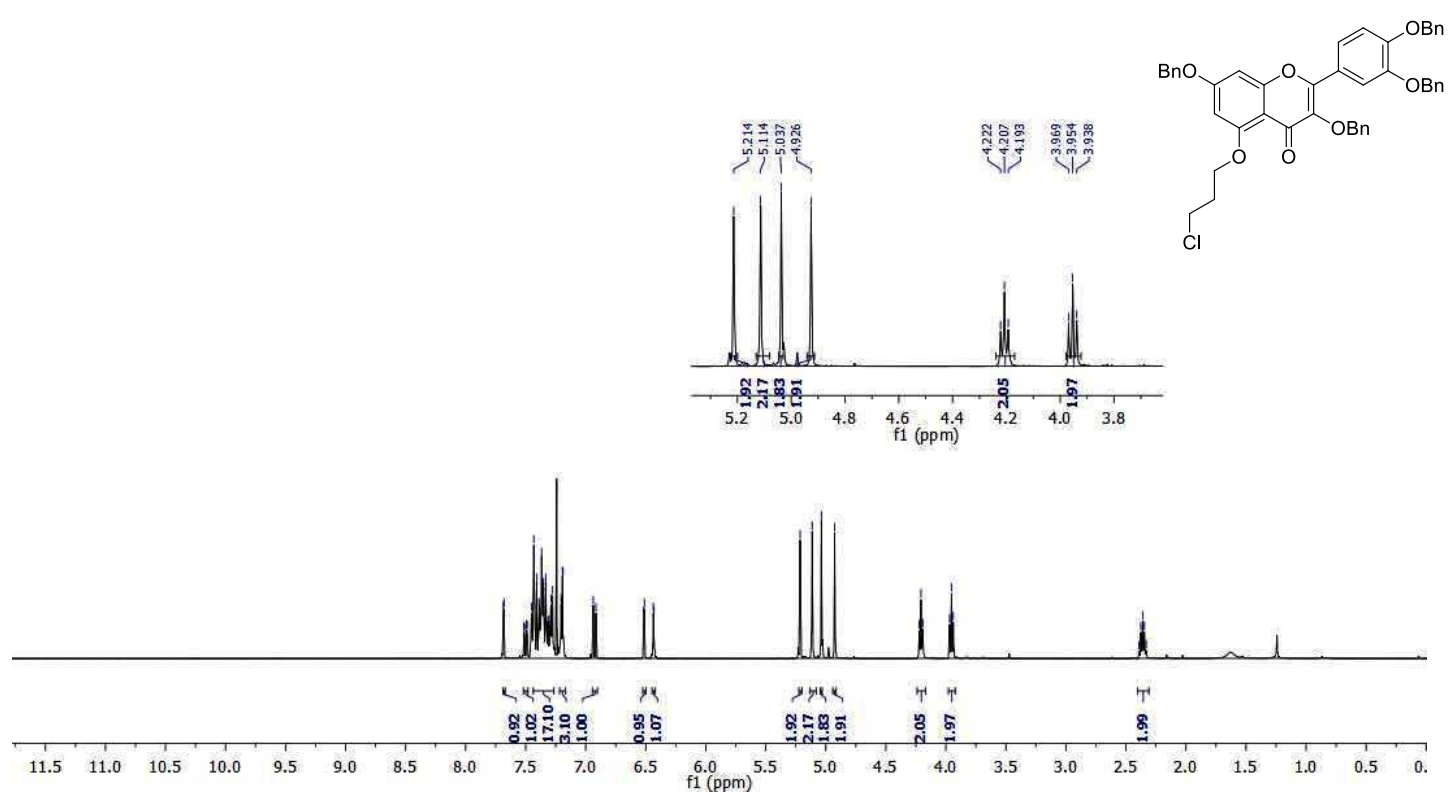

Carbon NMR

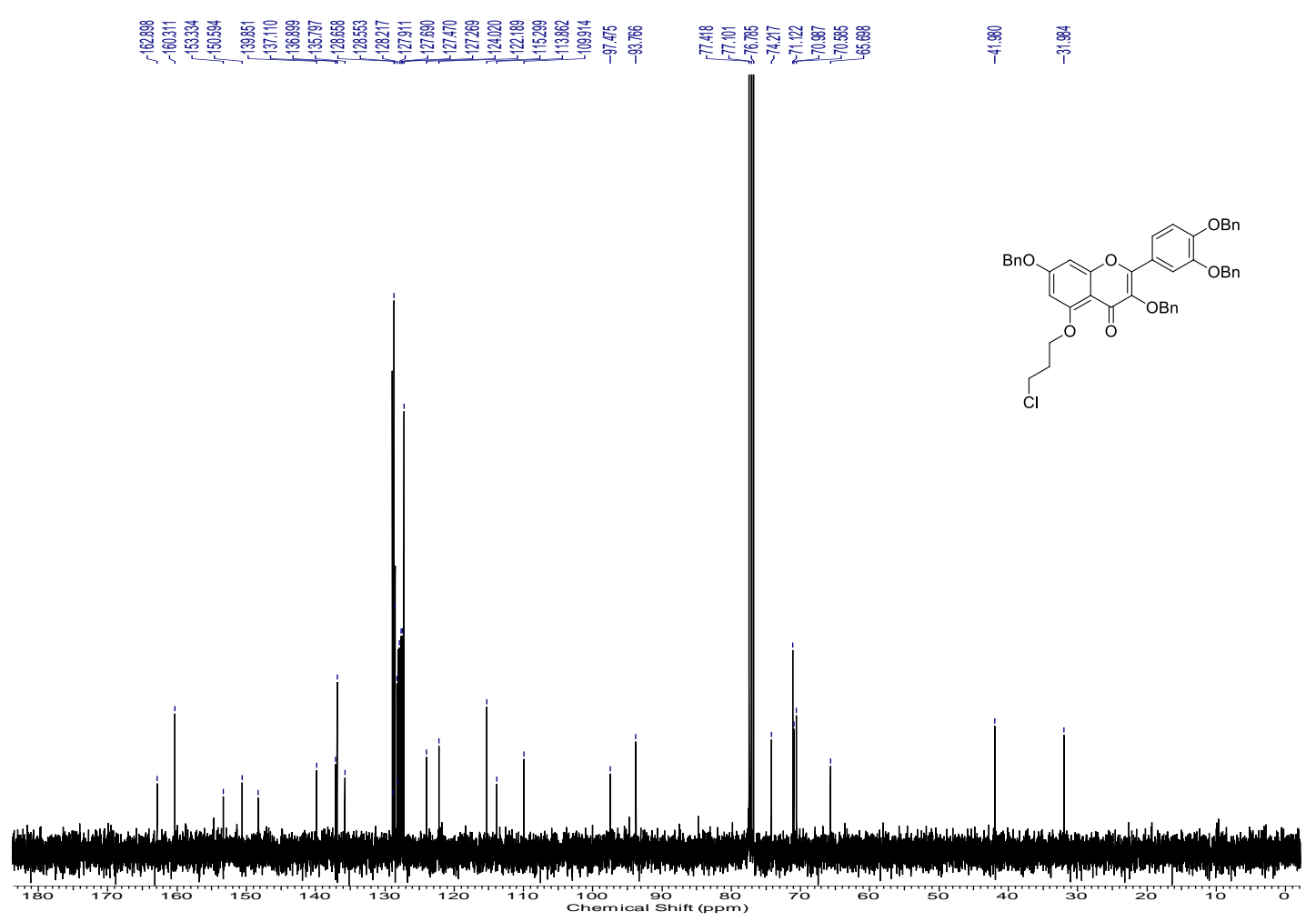


${ }^{1} \mathrm{H}$ NMR and ${ }^{13} \mathrm{C}$ NMR of Compound 22

Proton NMR

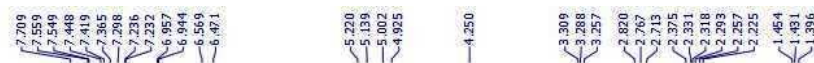

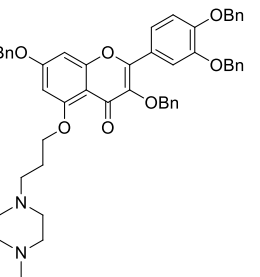

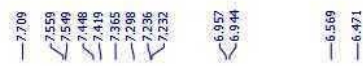
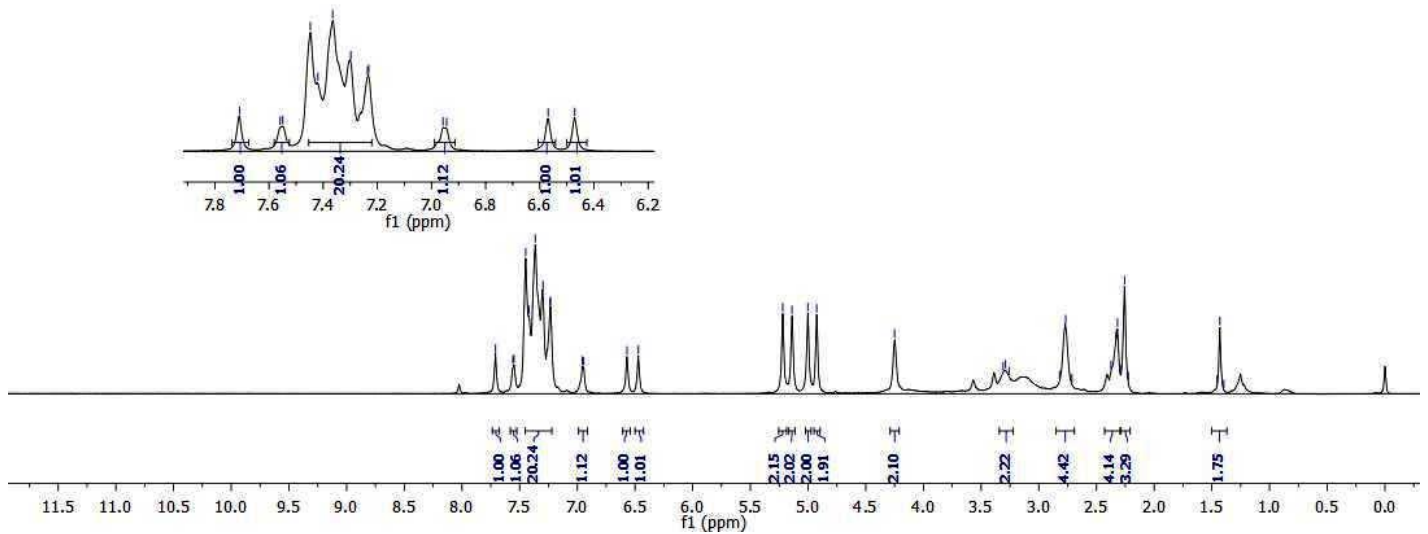

Carbon NMR

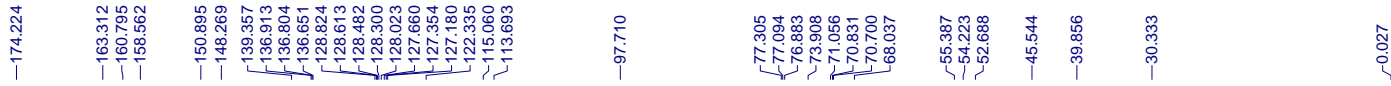

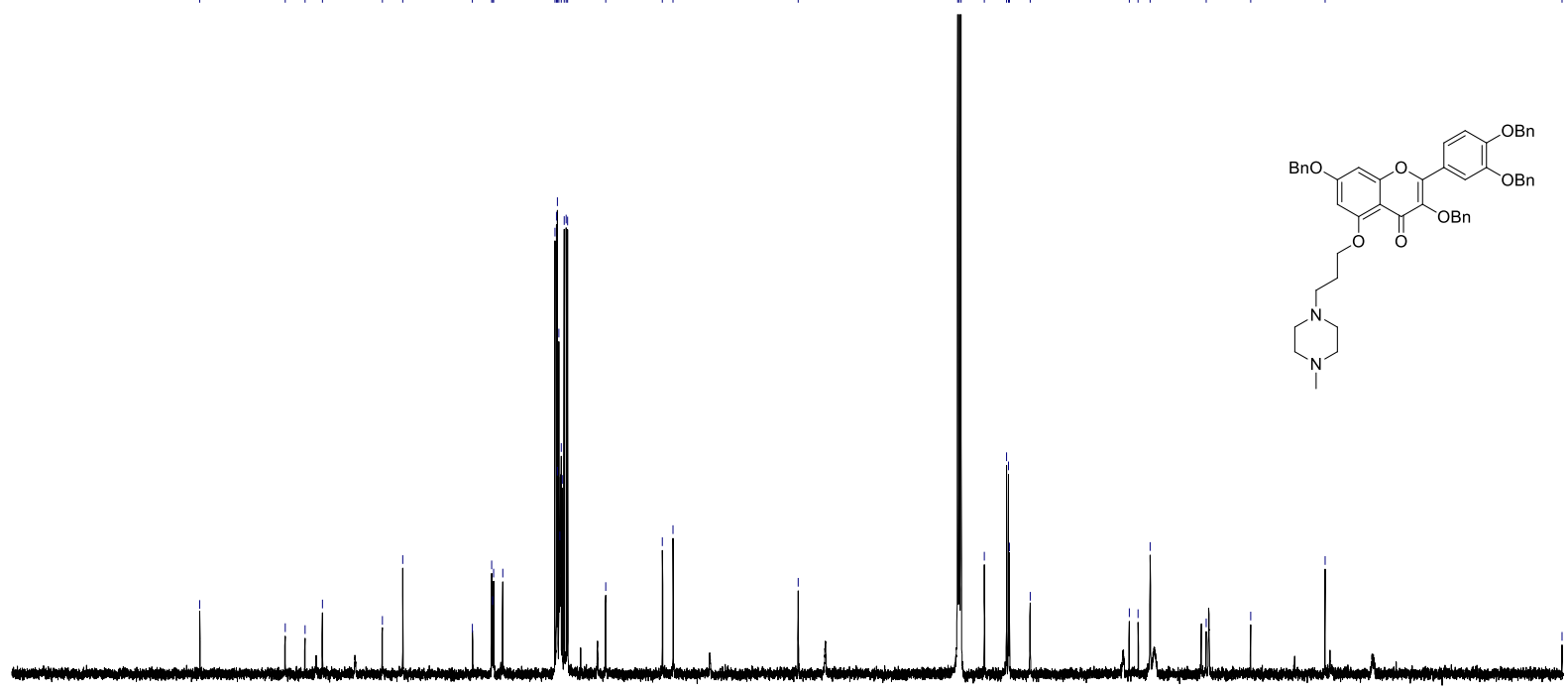

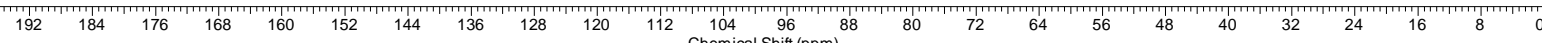


${ }^{1} \mathrm{H}$ NMR and ${ }^{13} \mathrm{C}$ NMR of Compound 23

Proton NMR

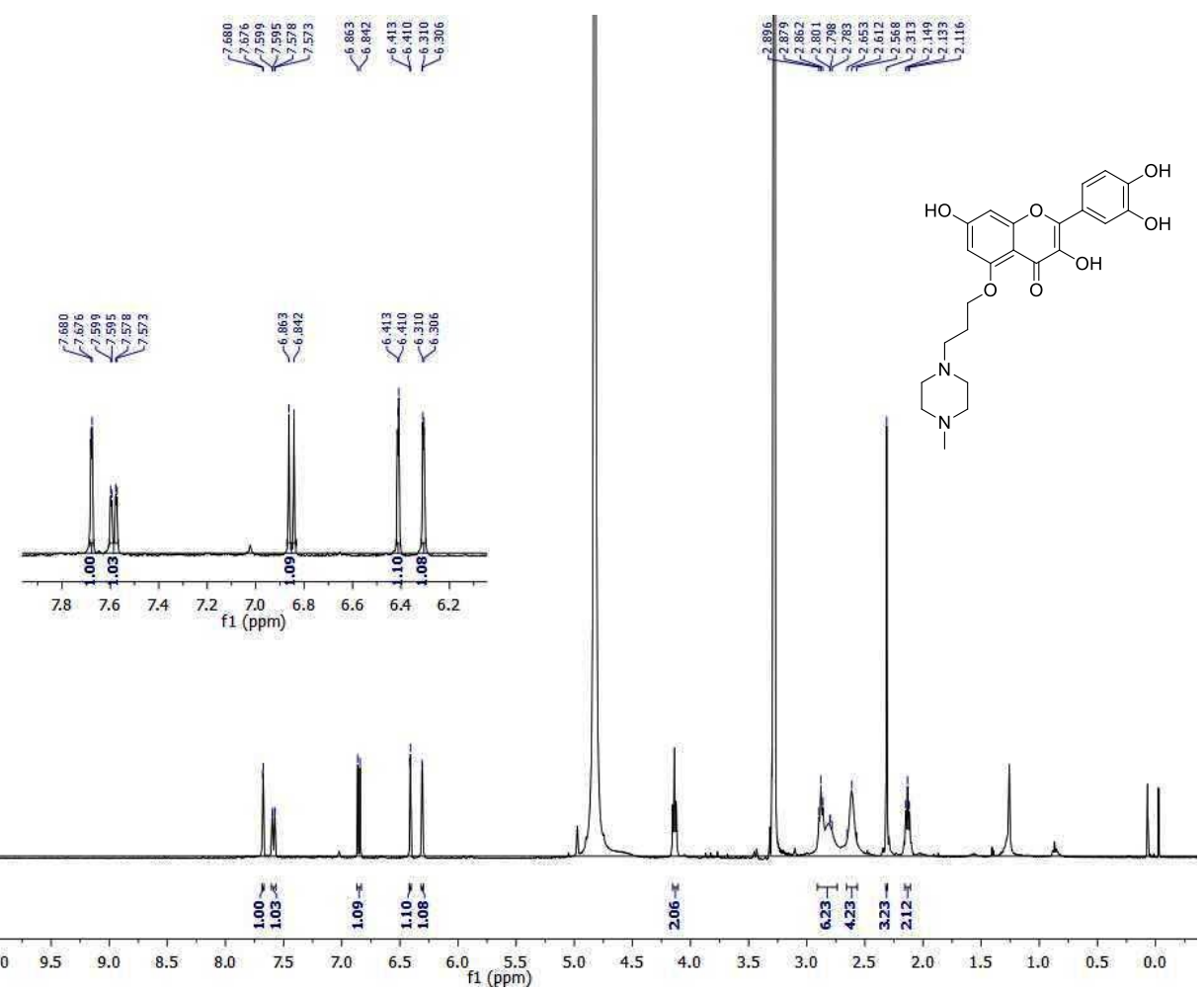

Carbon NMR

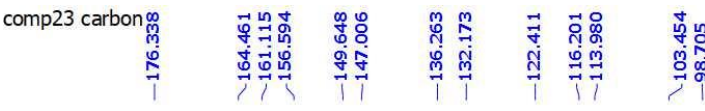
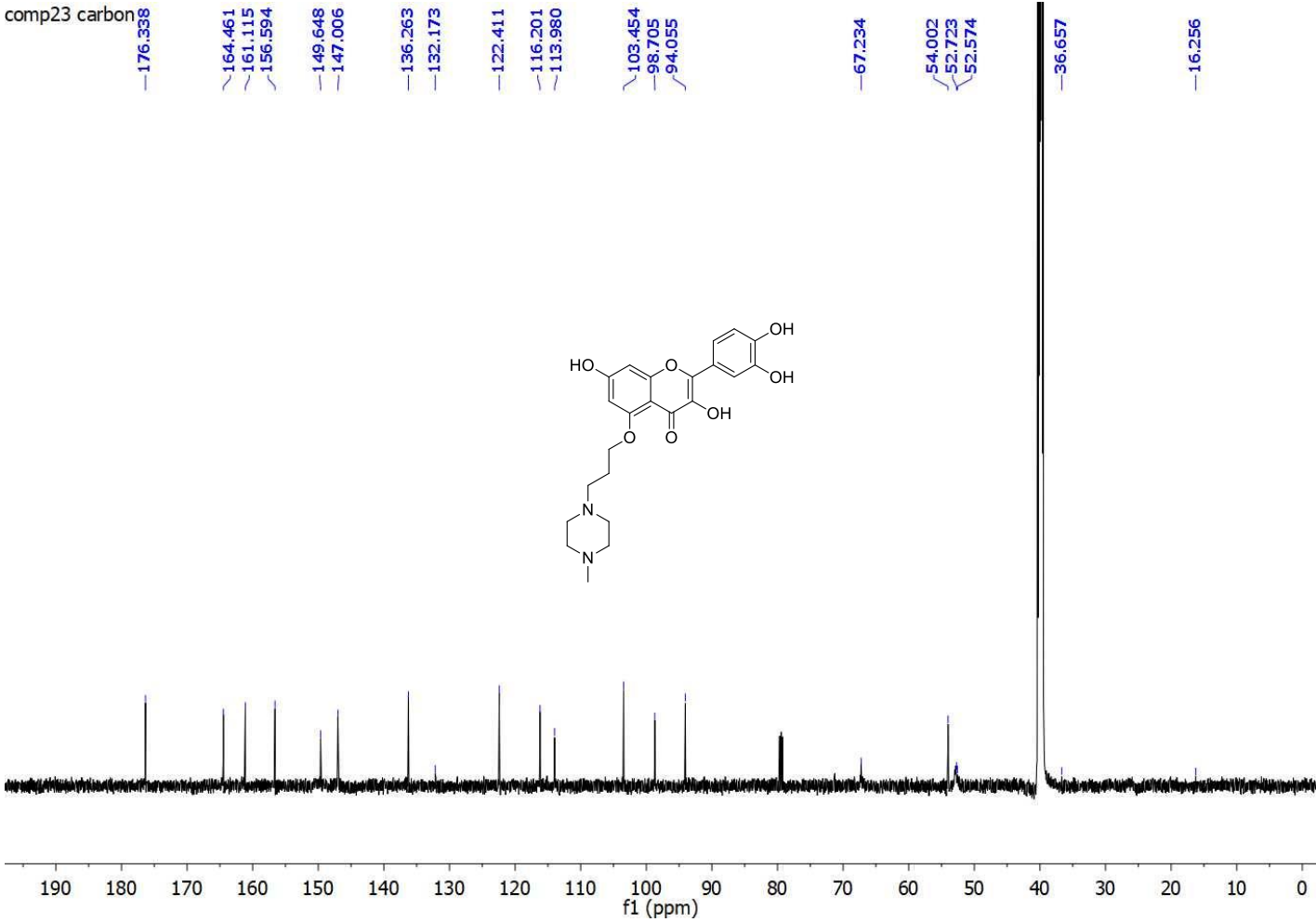
HRMS error value table

\begin{tabular}{|l|l|}
\hline Comp.No & Error $(\mathrm{ppm})$ \\
\hline $\mathbf{4}$ & 1.08 \\
\hline $\mathbf{5}$ & 4.28 \\
\hline $\mathbf{6}$ & 1.3 \\
\hline $\mathbf{7}$ & 1.1 \\
\hline $\mathbf{8}$ & 3.6 \\
\hline $\mathbf{9}$ & 0.9 \\
\hline $\mathbf{1 0}$ & 0.48 \\
\hline $\mathbf{1 1}$ & 4.02 \\
\hline $\mathbf{1 2}$ & 1.30 \\
\hline $\mathbf{1 3}$ & 0.92 \\
\hline $\mathbf{1 4}$ & 2.3 \\
\hline $\mathbf{1 5}$ & 0.84 \\
\hline $\mathbf{1 6}$ & 3.86 \\
\hline $\mathbf{1 7}$ & 0.67 \\
\hline $\mathbf{1 8}$ & 0.55 \\
\hline $\mathbf{1 9}$ & 3.01 \\
\hline $\mathbf{2 0}$ & 0.76 \\
\hline $\mathbf{2 1}$ & 0.81 \\
\hline
\end{tabular}




\section{Cell Viability assay in PBMC and HCT116 Cell line.}

A
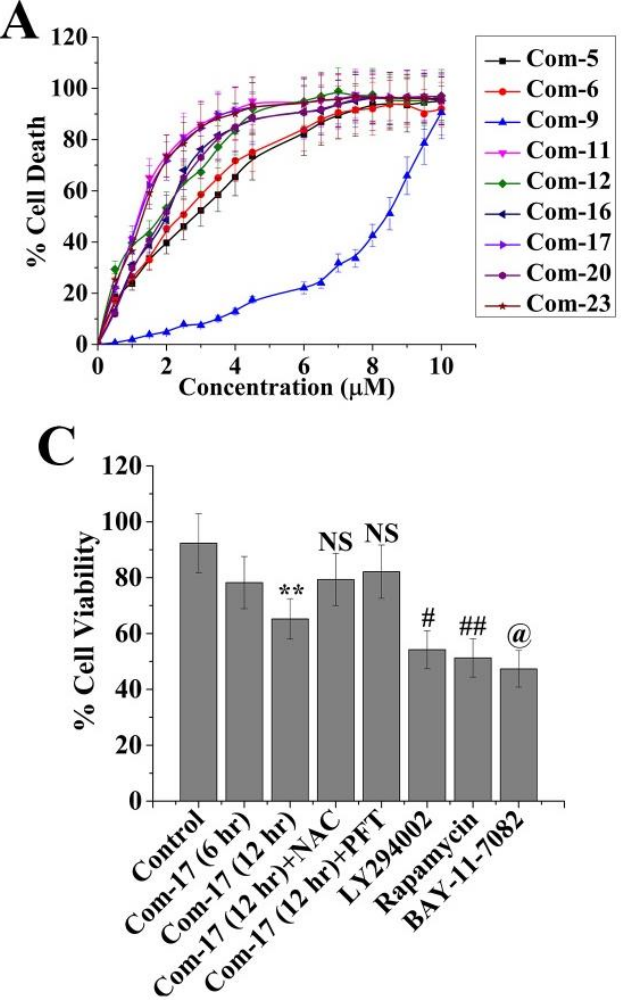

B

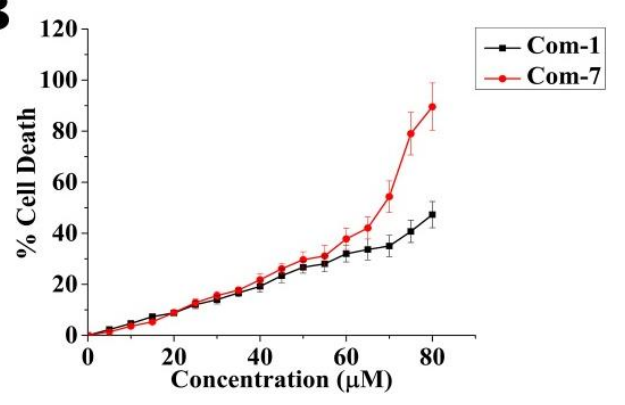

D

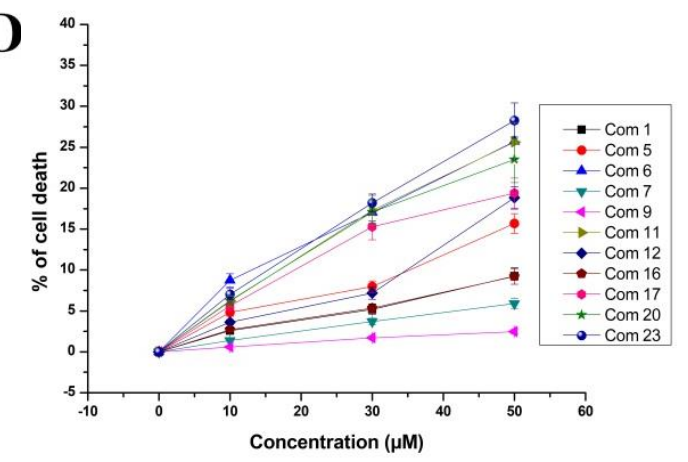

Figure S1. Assessment of cell viability upon the treatment of different quercetin derivatives. Percent cell death assessed by MTT assay in HCT-116 cells. (A) Cells exposed to Com-5, 6, $9,11,12,16,17,20$, and $23(0.5-10.0 \mu \mathrm{M})$ for $24 \mathrm{hr}$. (B) Cells exposed to Com-1 and 7 (5-80 $\mu \mathrm{M}$ ) for $24 \mathrm{hr}$. (C) Bar graph representing percent cell viability obtained from the treatment of Com-17 $(0.47 \mu \mathrm{M})$ for $6 \mathrm{hr}$ and $12 \mathrm{hr}$ along with/without of NAC, PFT- $\alpha$, LY294002, Rapamycin, BAY-11-7082 treatment. (D) Evaluation of percent cell death upon the treatment of various quercetin derivatives in PBMC cells for $24 \mathrm{hr}$. Values are represented as mean \pm SEM $(n=5) . p<0.05$ was considered as significant. 


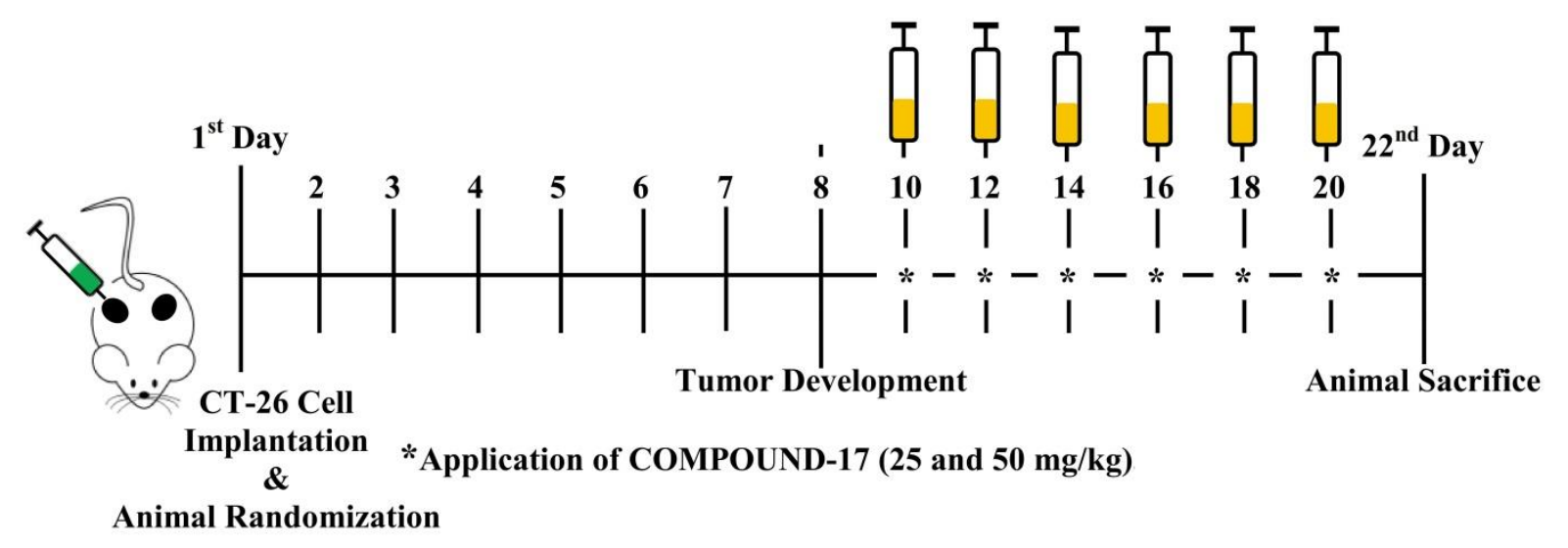

Figure S2. Schematic representation of the experimental design outlining the phases of CT26-challenge along with the Com-17 application (25 and $50 \mathrm{mg} / \mathrm{kg}$ ) in the murine system.

\section{Photo of harvest tumour}

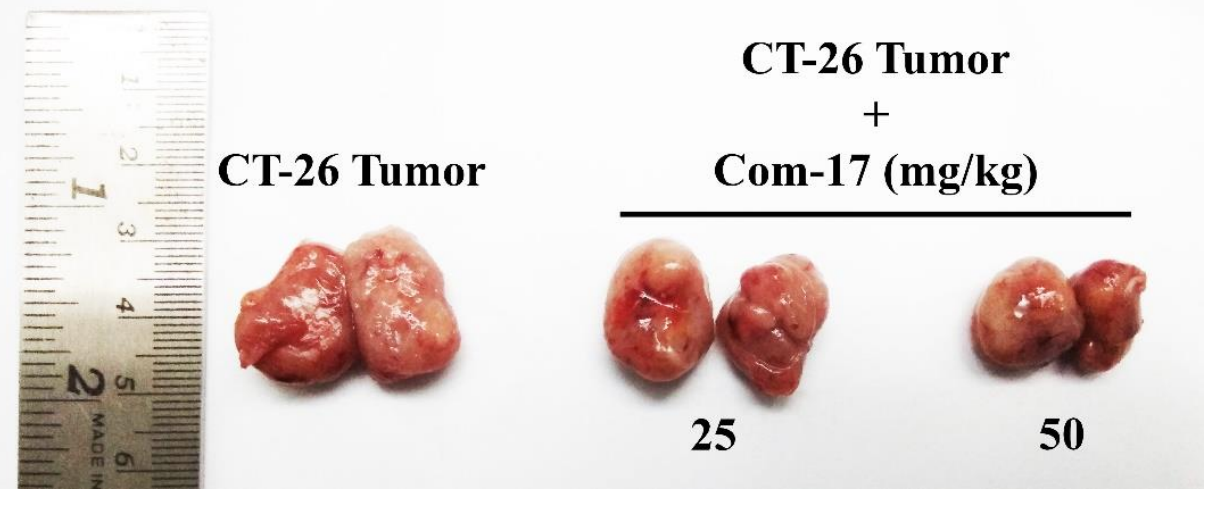

Figure S3. Photo of harvest tumour. The photo was taken by Dr. Krishnendu Manna (one of the author). 